\title{
Diapycnal heat flux and mixed layer heat budget within the Atlantic Cold Tongue
}

\author{
Rebecca Hummels • Marcus Dengler • Peter Brandt • \\ Michael Schlundt
}

Received: 31 October 2013 / Accepted: 10 September 2014 / Published online: 28 September 2014

(c) The Author(s) 2014. This article is published with open access at Springerlink.com

\begin{abstract}
Sea surface temperatures (SSTs) in the eastern tropical Atlantic are crucial for climate variability within the tropical belt. Despite this importance, state-of-the-art climate models show a large SST warm bias in this region. Knowledge about the seasonal mixed layer (ML) heat budget is a prerequisite for understanding SST mean state and its variability. Within this study all contributions to the seasonal ML heat budget are estimated at four locations within the Atlantic cold tongue (ACT) that are representative for the western $\left(0^{\circ} \mathrm{N}, 23^{\circ} \mathrm{W}\right)$, central $\left(0^{\circ} \mathrm{N}, 10^{\circ} \mathrm{W}\right)$ and eastern $\left(0^{\circ} \mathrm{N}, 0^{\circ} \mathrm{E}\right)$ equatorial as well as the southern $\left(10^{\circ} \mathrm{S}\right.$, $\left.10^{\circ} \mathrm{W}\right) \mathrm{ACT}$. To estimate the contribution of the diapycnal heat flux due to turbulence an extensive data set of microstructure observations collected during ten research cruises between 2005 and 2012 is analyzed. The results for the equatorial ACT indicate that with the inclusion of the diapycnal heat flux the seasonal ML heat budget is balanced. Within the equatorial region, the diapycnal heat flux is essential for the development of the ACT. It dominates over all other cooling terms in the central and eastern equatorial ACT, while it is of similar size as the zonal advection in the western equatorial ACT. In contrast, the
\end{abstract}

This paper is a contribution to the special issue on tropical Atlantic variability and coupled model climate biases that have been the focus of the recently completed Tropical Atlantic Climate Experiment (TACE), an international CLIVAR program (http://www.clivar.org/organization/atlantic/tace). This special issue is coordinated by William Johns, Peter Brandt, and Ping Chang, representatives of the TACE Observations and TACE Modeling and Synthesis working groups.

R. Hummels $(\bowtie) \cdot$ M. Dengler $\cdot$ P. Brandt $\cdot$ M. Schlundt GEOMAR Helmholtz Centre for Ocean Research, Düsternbrooker Weg 20, 24105 Kiel, Germany

e-mail: rhummels@geomar.de
SST evolution in the southern ACT region can be explained entirely by air-sea heat fluxes.

Keywords Mixed layer heat budget - Atlantic Cold Tongue region · Diapycnal heat flux $\cdot$ Microstructure observations

\section{Introduction}

The tropical Atlantic ocean plays a key role for climate variability in sensitive regions of the surrounding continents: Previous studies suggest that inter-annual variability of sea surface temperature (SST) in the equatorial Atlantic impacts rainfall variability over northeast Brazil and the coastal regions surrounding the Gulf of Guinea (Chang et al. 2006; Kushnir et al. 2006; Brandt et al. 2011b). In particular, inter-annual SST variability within the Atlantic cold tongue (ACT) is known to influence the onset and strength of the West African Monsoon (Marin et al. 2009; Brandt et al. 2011a; Caniaux et al. 2011). Hence, in order to improve predictions of rainfall variability, SST variability and its causes need to be understood.

Sea surface temperature variability in the tropical Atlantic is dominated by an annual signal formed by the seasonal appearance of the ACT (Fig. 1). During the development of the ACT in boreal spring/summer SSTs decrease by about $6{ }^{\circ} \mathrm{C}$. Towards the end of the year SSTs steadily increase completing the annual cycle (Fig. 2a). On the other hand, the net surface heat fluxes within this region are dominated by a semi-annual signal due to the meridional migration of the Inter Tropical Convergence Zone (ITCZ). The discrepancy between the semi-annual atmospheric forcing and the annual cycle of SSTs suggests ocean dynamics to be of fundamental importance within this region. Furthermore, the 
Fig. 1 Satellite SSTs (TMI) in July 2001 showing the regional extent of the ACT. The four locations of the PIRATA buoys used for this study are marked by red rectangles. The black lines denote the area used for evaluating the average diapycnal heat flux included in the ML budget

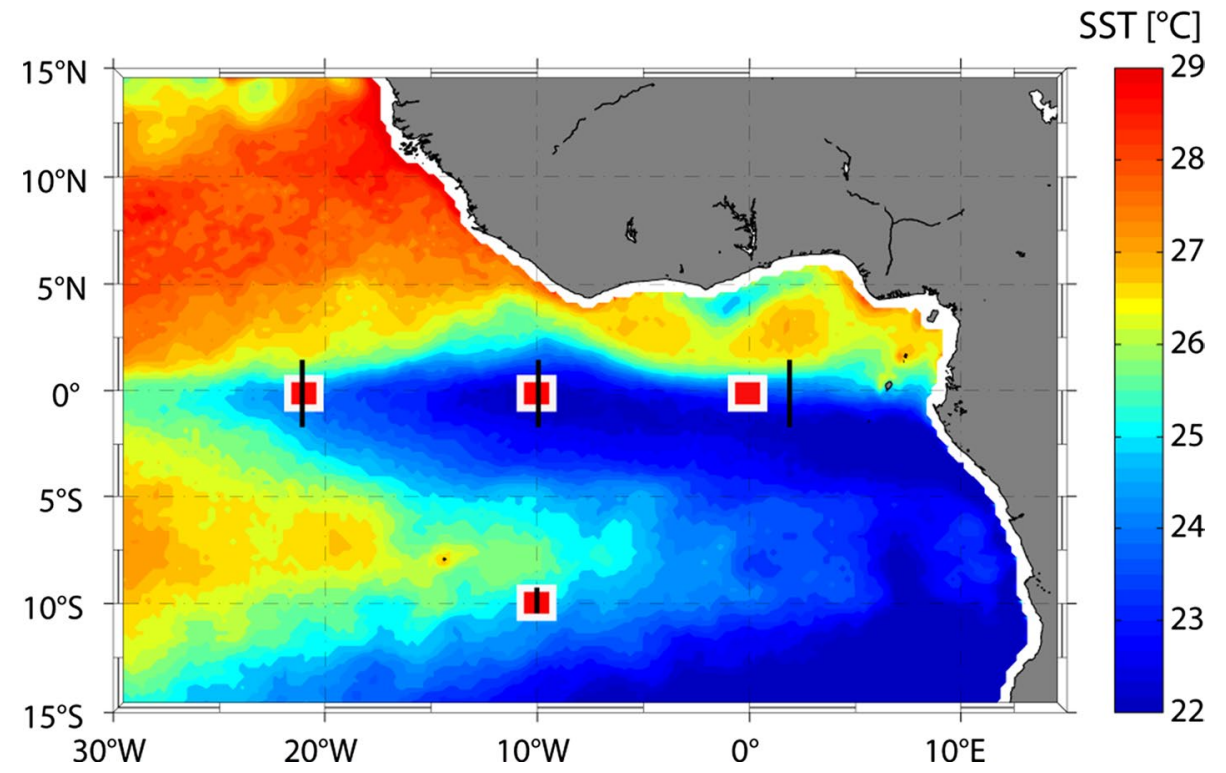

$\mathrm{ACT}$ is the oceanic region with strongest net atmospheric heat gain in the Atlantic (Josey et al. 1999). Hence, in order to reduce SST during ACT development, oceanic processes need to redistribute large amounts of heat to explain the observed seasonal decrease of SST. To further understand the seasonal cycle of SSTs within this region, an analysis of all individual contributions to the mixed layer (ML) heat budget is inevitable.

Several investigations of the ML heat budget in the ACT region either rely on model simulations (Peter et al. 2006; Jouanno et al. 2011b) or observational data (Foltz et al. 2003; Wade et al. 2011; Hummels et al. 2013). Both approaches have their advantages and deficiencies. Model approaches can consistently evaluate the ML heat budget including all individual contributions. However, model results might be biased due to their sensitivity to the parameterization of unresolved physics, e.g. horizontal and vertical mixing. On the other hand, observational studies often lack information on individual terms of the budget, which can not be estimated from the available data sets. In addition, some of the estimated terms may lack reliability due to a limited data base in time and/or space.

Previous observational studies investigating the ML heat budget in the ACT region follow different approaches in order to exploit the existing data sets in the best possible way. Nevertheless, many of these studies lack information on the contribution of the diapycnal heat flux due to turbulent mixing at the base of the ML to the heat budget. Instead, this term is assessed as the residual of the budget, which additionally includes all accumulated uncertainties (Foltz et al. 2003, 2013; Wade et al. 2011). Model studies of the ACT as well as the Pacific cold tongue (PCT) have suggested that diapycnal mixing is an important contributor to the ML heat budget (Chang 1993; Peter et al. 2006;
Jouanno et al. 2011b). In an observational study, Gouriou and Reverdin (1992) suggested diapycnal mixing to vary seasonally within the ACT.

It was only recently that measurement programs could indeed resolve seasonal variability of upper ocean turbulence: From multi-year moored microstructure temperature measurements Moum et al. (2013) demonstrated that diapycnal mixing indeed controls the seasonal cooling within the PCT at $0^{\circ} \mathrm{N}, 140^{\circ} \mathrm{W}$, while for the equatorial ACT (i.e. within the equatorial belt $2^{\circ} \mathrm{S}-1.5^{\circ} \mathrm{N}, 23^{\circ} \mathrm{W}-2^{\circ} \mathrm{E}$ ), Hummels et al. (2013) highlighted seasonal and regional differences in diapycnal heat flux from the ML into the upper thermocline using a multi-cruise microstructure profiling data set. Hummels et al. (2013) found that the ML heat loss due to diapycnal mixing is of considerable magnitude and amounts to up to $90 \mathrm{~W} \mathrm{~m}^{-2}$ within the equatorial ACT region.

By solving the ML heat balance on the equator at $10^{\circ} \mathrm{W}$, Hummels et al. (2013) showed that the diapycnal ML heat loss is the dominant cooling term for the ML heat budget during ACT development. In fact, they were able to balance the seasonal ML heat budget at this location for the period from May to November when incorporating estimates of the diapycnal heat flux. In the ACT as well as in the PCT region, turbulent mixing could be associated with shear instabilities (Gregg et al. 1985; Hummels et al. 2013). Within the entire equatorial ACT vertical shear of horizontal velocity is significantly elevated due to opposing currents, namely the westward-directed northern branch of the South Equatorial Current (nSEC) at the surface and the Equatorial Undercurrent (EUC) flowing eastward along the thermocline. Accordingly, the diapycnal heat flux estimated from individual cruises carried out at different locations within the equatorial ACT is elevated (Hummels et al. 2013). This suggests that diapycnal mixing could be 
Fig. 2 Seasonal variability of different variables at the four different PIRATA buoy sites (color code is given in legend): a SST (PIRATA), b net surface heat flux corrected for the amount of heat penetrating the ML (TropFlux), c MLD (PIRATA), d wind stress magnitude (TropFlux), e zonal surface velocities (Argo + drifter climatology), f meridional surface velocities (Argo + drifter climatology). Error bars denote $95 \%$ confidence limits and are calculated as explained in Appendix 3
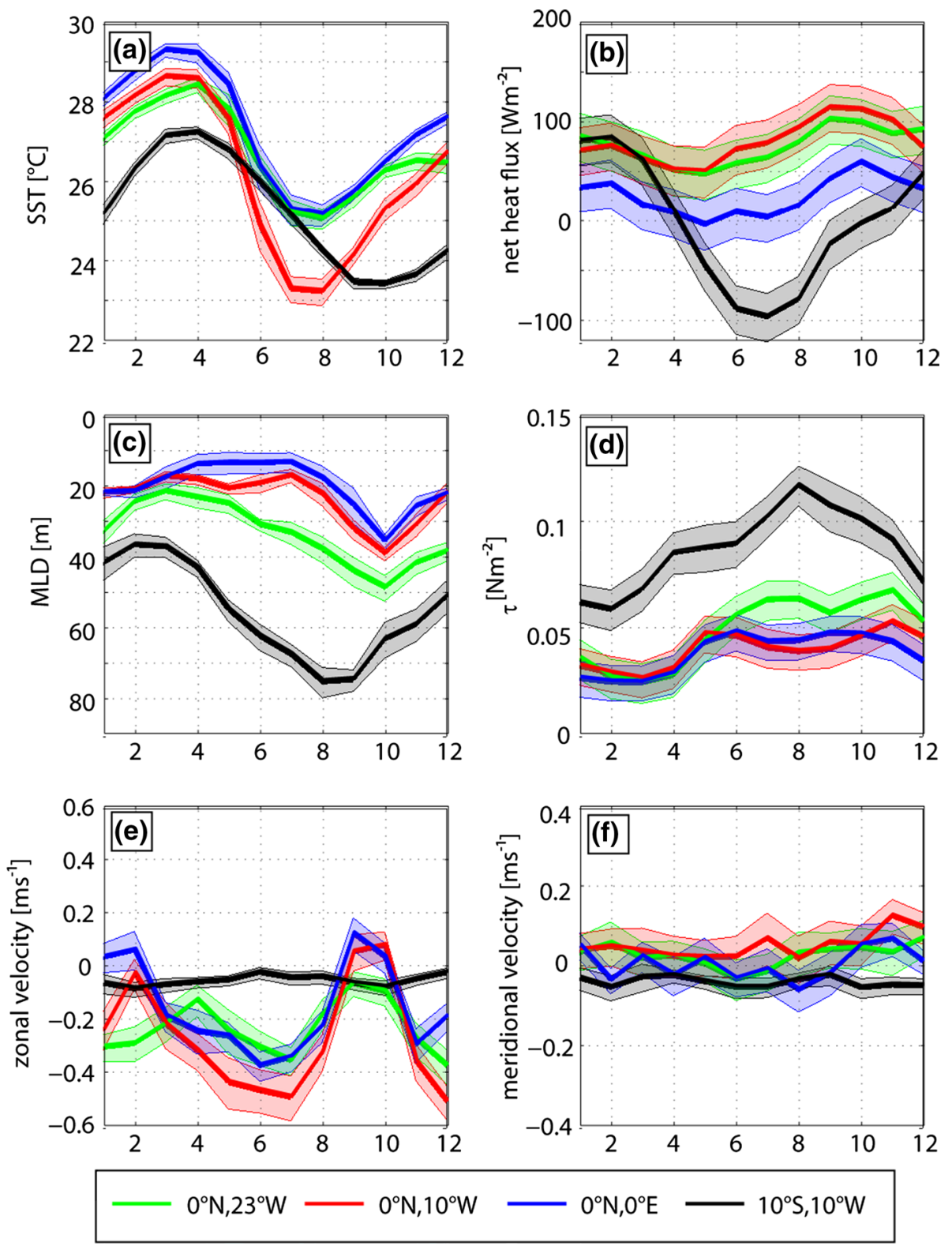

important for the ML heat budget in the entire equatorial ACT region. The importance of diapycnal mixing for the ML heat budget associated with shear instabilities forced by the nSEC/EUC system within the equatorial ACT was previously diagnosed in numerical simulations (Jouanno et al. 2011a, b).

However, elevated diapycnal heat flux appears to be confined to the equatorial band $\left(2^{\circ} \mathrm{S}\right.$ to $\left.1^{\circ} \mathrm{N}\right)$ only. At the southern tip of the ACT at $10^{\circ} \mathrm{S}, 10^{\circ} \mathrm{W}$, Hummels et al. (2013) find diapycnal ML heat loss to be considerably lower (their Fig. 15), which suggests other mechanisms are important to reduce SSTs in the off-equatorial ACT.

This study is motivated by the success of Hummels et al. (2013) in achieving a balance of the ML heat fluxes and tendency at the equator at $10^{\circ} \mathrm{W}$ between May and
November during the times when estimates of the diapycnal heat flux were available and could be included. Our intention here is to clarify whether a closure of the ML heat budgets from different locations within the ACT can be achieved when explicitly incorporating estimates of the diapycnal heat flux from microstructure observations and to assess the relative contribution of the diapycnal ML heat loss to the budgets at the different locations. The diapycnal heat flux observations reported by Hummels et al. (2013) are complemented with some recent cruises and combined with long-term observations from the Prediction and Research moored Array in the Tropical Atlantic (PIRATA; Bourlès et al. 2008) and climatological products to estimate a seasonal climatology of the tendency and the flux terms contributing to the heat budget of the ML at different 
Table 1 Spatial and temporal distribution of microstructure profiles available to this study

\begin{tabular}{|c|c|c|c|c|c|}
\hline ACT phase & $\begin{array}{l}\text { Time period of used } \\
\text { MSS observations }\end{array}$ & Vessel and Cruise ID & Sections & $\begin{array}{l}\text { Number of stations } \\
\left(2^{\circ} \mathrm{S}-1.5^{\circ} \mathrm{N}\right)\end{array}$ & $\begin{array}{l}\text { Number of profiles } \\
\left(2^{\circ} \mathrm{S}-1.5^{\circ} \mathrm{N}\right)\end{array}$ \\
\hline Absence & 29/02-07/03/2008 & N/O L'Atalante GEOMAR 4 & $23^{\circ} \mathrm{W}$ & 16 & 78 \\
\hline \multirow[t]{4}{*}{ Development } & 01/06-03/07/2006 & N/O L'Atalante EGEE3 & $10^{\circ} \mathrm{W}(\mathrm{eq})$ & 15 & 45 \\
\hline & & & $10^{\circ} \mathrm{W}$ (south) & 8 & 24 \\
\hline & & & $2^{\circ} \mathrm{E}$ & 8 & 43 \\
\hline & & & $6^{\circ} \mathrm{E}$ & 5 & 15 \\
\hline \multirow[t]{2}{*}{ Development } & $17 / 06-01 / 07 / 2006$ & R/V Meteor M68/2 & $23^{\circ} \mathrm{W}$ & 8 & 39 \\
\hline & & & $10^{\circ} \mathrm{W}$ & 7 & 21 \\
\hline \multirow[t]{2}{*}{ Development } & 07/06-14/06/2007 & N/O L'Antea EGEE5 & $2^{\circ} \mathrm{E}$ & 8 & 24 \\
\hline & & & $6^{\circ} \mathrm{E}$ & 6 & 17 \\
\hline Development & $17 / 05-09 / 06 / 2011$ & R/V Maria S. Merian MSM18/2 & $23^{\circ} \mathrm{W}$ & 17 & 50 \\
\hline Mature & $12 / 09 /-14 / 09 / 2005$ & N/O Le Suroit EGEE2 & $10^{\circ} \mathrm{W}$ & 8 & 25 \\
\hline \multirow[t]{4}{*}{ Mature } & 04/09-24/09/2007 & N/O L'Antea EGEE6 & $10^{\circ} \mathrm{W}$ & 8 & 24 \\
\hline & & & $0^{\circ} \mathrm{E}$ & 9 & 29 \\
\hline & & & $2^{\circ} \mathrm{E}$ & 7 & 21 \\
\hline & & & $6^{\circ} \mathrm{E}$ & 7 & 21 \\
\hline \multirow[t]{2}{*}{ Mature } & 20/11-29/11/2006 & N/O L'Antea EGEE4 & $10^{\circ} \mathrm{W}$ & 7 & 21 \\
\hline & & & $2^{\circ} \mathrm{E}$ & 8 & 24 \\
\hline Mature & 02/11-13/11/2009 & R/V Meteor M80/1 & $23^{\circ} \mathrm{W}$ & 21 & 84 \\
\hline \multirow[t]{2}{*}{ Mature } & $04 / 11-12 / 11 / 2012$ & R/V Maria S. Merian MSM22 & $23^{\circ} \mathrm{W}$ & 5 & 10 \\
\hline & & & & $\Sigma 178$ & $\Sigma 615$ \\
\hline
\end{tabular}

Usually, at least three microstructure profiles were collected on each station. Each of those ensembles was used to infer diapycnal heat fluxes to include into the ML heat budgets (see Sect. 3c)

locations within the ACT. Furthermore, as microstructure data is only sparsely available, a parameterization for mixing based on stratification and shear is developed from the available data.

In Sect. 2 of this study the data set and method to calculate all individual contributions to the ML heat budget will be presented. Section 3 points out the different background setting at the four locations in the western $\left(23^{\circ} \mathrm{W}\right)$, central $\left(10^{\circ} \mathrm{W}\right)$ and eastern $\left(0^{\circ} \mathrm{E}\right)$ equatorial as well as southern $\left(10^{\circ} \mathrm{S}, 10^{\circ} \mathrm{W}\right) \mathrm{ACT}$ region. It also includes a description of turbulent mixing within the ACT and the results on the ML heat budgets at the four locations. The results are summarized and further discussed in Sect. 4.

\section{Data and methods}

In order to accomplish a seasonal description of the ML heat budget within the ACT, several data sets are combined. A limiting factor is the availability of estimates of the diapycnal heat flux due to mixing processes across the base of the ML. This term is derived from estimates of the turbulent dissipation rates inferred from observations made by microstructure profilers during a multi-cruise program (Hummels et al. 2013). During this program several meridional transects were frequently repeated during different stages of ACT development covering the absence (January-April), the development (April-July) and the mature phase (August-December) of the ACT (Caniaux et al. 2011). The highlighted transects were conducted across the equator $\left(2^{\circ} \mathrm{S}-1.5^{\circ} \mathrm{N}\right)$ along $23^{\circ} \mathrm{W}$, $10^{\circ} \mathrm{W}$ and $2^{\circ} \mathrm{E}$ (see Fig. 1, Table 1). At the equatorial position of these transects (or close to the transect in the case of the $2^{\circ} \mathrm{E}$ transect), atmospheric and oceanic PIRATA observations are available at high temporal resolution (Fig. 1). Hence, all terms contributing to the ML heat budget will be estimated at the four PIRATA buoy sites at $0^{\circ} \mathrm{N}, 23^{\circ} \mathrm{W}$; $0^{\circ} \mathrm{N}, 10^{\circ} \mathrm{W} ; 0^{\circ} \mathrm{N}, 0^{\circ} \mathrm{E}$ and $10^{\circ} \mathrm{S}, 10^{\circ} \mathrm{W}$. For the determination of the contribution of the heat flux due to advection additional information on surface velocities, SST and mixed layer depth (MLD) as well as their horizontal gradients are required from climatological products.

\subsection{Shipboard observations}

A unique data set of microstructure shear and temperature profiles along with conductivity-temperature-depth (CTD) profiles was collected on ten cruises to the ACT region during different stages of ACT development (Table 1). The multicruise program includes cruises of the French EGEE (Etude de la circulation océanique et des échanges océan-atmosphère 
dans le Golfe de Guinée) project (EGEE2-6) and the German projects Nordatlantik (M68/2, MSM18/2) and SFB754 (M80/1, GEOMAR4, MSM22). Four cruises (EGEE3, EGEE5, M68/2 and MSM18/2) were scheduled to coincide with the development of the ACT and onset of the West African Monsoon in boreal spring and early summer (end of May to July), while another two cruises (EGEE2 and EGEE6) were carried out during the mature phase of the monsoon (September-October), when the ACT is still well developed. Finally, three cruises (EGEE4, M80/1 and MSM22) were conducted in November while the ACT was warming. Another cruise was undertaken during the absence of the ACT in March 2008 (GEOMAR4).

Due to the latitudinal extent of the EUC, meridional transect data collected in the equatorial belt between $2^{\circ} \mathrm{S}$ and $1.5^{\circ} \mathrm{N}$ are representative of the mixing activity at the equator (Hummels et al. 2013). Hence, to improve the statistics of the equatorial estimate of the diapycnal ML heat loss due to turbulence, all available profiles in this latitudinal range are used. The only stations evaluated outside the equatorial belt were collected near $10^{\circ} \mathrm{S}, 10^{\circ} \mathrm{W}$ during EGEE3. For more details on the cruises the reader is referred to Hummels et al. (2013).

The microstructure shear and temperature data were collected using different microstructure profilers (MSS90L and MSS90D) manufactured by Sea\&Sun Technology in cooperation with ISW-Wassermesstechnik. All profilers were equipped with two shear sensors (airfoil), a fast temperature sensor (FP07), an acceleration sensor, tilt sensors and standard CTD sensors. For a detailed description of the instruments the reader is referred to Prandke and Stips (1998). The profilers were adjusted to descend at $0.5-0.6 \mathrm{~m} \mathrm{~s}^{-1}$. Noise levels of turbulent dissipation rates from the microstructure profilers are better than $1 \times 10^{-9} \mathrm{~W} \mathrm{~kg}^{-1}$ for the MSS90L and better than $5 \times 10^{-10} \mathrm{~W} \mathrm{~kg}^{-1}$ for MSS90D (Prandke and Stips 1998; Schafstall et al. 2010).

The sampling strategy pursued for the different cruises differs in comparison to previous microstructure studies conducted in the equatorial Pacific. Instead of sampling at a single location for a period of several days to several weeks (Peters et al. 1988; Moum et al. 1989, 2009; Lien et al. 1995; Inoue et al. 2012), profiling was done at several locations during a single cruise usually separated by $0.5^{\circ}$ latitude on the meridional transects. This was accomplished by integrating microstructure profiling into the CTD station program during all cruises. A minimum of 3 and up to 20 microstructure profiles were collected at a single station extending from the surface to between 150 and $300 \mathrm{~m}$ depth. For this study a total of 615 profiles collected on 178 stations are used.

A few microstructure profiles from a more recent cruise conducted on R/V Maria S. Merian in summer 2011, MSM18/2, were not considered in this study. R/V Maria
S. Merian was put into service in 2006 and ship-board microstructure observations had not been performed in the equatorial region prior to this cruise. Although most of the profiles collected during MSM18/2 were in the range of previously collected profiles from the same location and season, a few extreme events in water depths between 15 and $50 \mathrm{~m}$ were observed in single profiles. Here, turbulent dissipation rates reach up to $5 \times 10^{-5} \mathrm{~W} \mathrm{~kg}^{-1}$. These intense mixing events that were associated with very short time scales of $<30$ min were not evident in the other profiles from similar locations during the previous 9 cruises. Similarly, microstructure data collected from a Slocum glider equipped with a microstructure probe (MicroRider, manufactured by Rockland Scientific) during the period of the cruise did not show mixing events of similar magnitude during a 26 day record from the equator at $10^{\circ} \mathrm{W}$. We thus assume that the presence of the R/V Maria S. Merian triggered Kelvin-Helmholtz instabilities in the water column locally, but the exact process could not be assessed. Although these extreme events pass through all quality control procedures in post-processing, it was decided to remove the three affected profiles from the data set of this cruise, as the source of these extremely short events remains ambiguous. The remaining MSM18/2 cruise data used here thus consists of 50 profiles from 17 stations.

\subsubsection{Microstructure data processing}

Processing of microstructure data and further inferring eddy diffusivities $\left(K_{\rho}\right)$ and diapycnal heat fluxes $\left(J_{h}\right)$ out of the ML is explained in detail in Hummels (2012) and Hummels et al. (2013). A summary is given below.

In the Reynolds-averaged equation for turbulent kinetic energy (TKE) the TKE dissipation rate $(\varepsilon)$ is given by

$\varepsilon=\overline{v \frac{\partial u_{i}}{\partial x_{j}}\left(\frac{\partial u_{i}}{\partial x_{j}}+\frac{\partial u_{j}}{\partial x_{i}}\right)}$,

where $u$ refers to the turbulent velocity fluctuations, $x$ refers to the spatial coordinate system and the standard tensor notation of summing over three components is used (e.g. in Moum et al. 1995); $v$ is the kinematic viscosity of seawater. Under the assumption of local isotropy, these 12 terms are simply related leaving only one independent component to be estimated: $\varepsilon=7.5 v \overline{\left[\frac{\partial u}{\partial z}\right]^{2}}$ (Hinze 1975; Pope 2000). For this study, dissipation rates of turbulent kinetic energy were determined from the airfoil shear data recorded at the sampling rate of $1024 \mathrm{~Hz}$ via the variance method. In fact, the shear wave number spectra, $E_{\mathrm{du} / \mathrm{d} z}$, are related to the turbulent dissipation rate through integration, $\varepsilon=7.5 v \int_{k_{\min }}^{k_{\max }} E_{\mathrm{du} / \mathrm{d} z}(k) \mathrm{d} k$ (e.g. Gregg 1998). The shear 
wave number spectra were calculated from 1-s ensembles ( 1,024 values) corresponding to a vertical interval of $0.5-$ $0.6 \mathrm{~m}$. After the integration is performed, a variance loss correction due to the limited resolved wavenumber band between $k_{\min }$ and $k_{\max }$, which were iteratively adjusted as explained in Schafstall et al. (2010), is applied by fitting to the universal Nasmyth spectrum (Oakey 1982).

Turbulent eddy diffusivities for mass were estimated from dissipation rates of turbulent kinetic energy $(\varepsilon)$ using the dissipation method of Osborn (1980): $K_{\rho}=\Gamma \varepsilon N^{-2}$. Here, $\Gamma$ is the mixing efficiency and set to the constant value of 0.2 (for details see Hummels et al. 2013) and $\mathrm{N}^{-2}$ is the inverse of the buoyancy frequency. Buoyancy frequency was calculated from least squared fits to salinity and temperature using a depth interval of up to $30 \mathrm{~m}$ or less ( $3 \mathrm{~m}$ directly below the ML) to avoid biases in stratification. Furthermore, the diapycnal heat flux is calculated via $J_{h}=-\rho c_{p} K_{\rho} \frac{\partial T}{\partial z}$ with $\rho$ and $c_{p}$ being the density of seawater and specific heat capacity, respectively, and $\frac{\partial T}{\partial z}$ the vertical temperature gradient. Eddy diffusivity and diapycnal heat flux profiles are calculated separately for every station with average station profiles of turbulent dissipation rates obtained from the individual profiles.

\subsection{PIRATA data}

For evaluating the ML heat budgets, incoming solar radiation, subsurface temperature time series, air temperature, relative humidity, wind speed and rainfall data from the PIRATA buoy sites at $23^{\circ} \mathrm{W}, 10^{\circ} \mathrm{W}$ and $0^{\circ} \mathrm{E}$ on the equator as well as at $10^{\circ} \mathrm{S}, 10^{\circ} \mathrm{W}$ were used. To determine the mean seasonal cycle, we used all available daily averages from 1997 to 2012.

\subsection{Climatological products}

\subsubsection{Surface velocities}

Near-surface velocities are constructed from a combination of the YoMaHa'07 (Lebedev et al. 2007) data set providing surface velocities from ARGO float surface drifts and surface velocities from drifters (www.aoml.noaa. gov/phod/dac/). The combination of data from different platforms enhances the available data base, which is in general limited as the equatorial region is characterized by diverging poleward flow and drifters (and to some extent also ARGO floats) tend to leave the equatorial region shortly after their deployment. Drifters are designed to follow the mean currents of the upper $15 \mathrm{~m}$ due to the attachment of a drogue, while ARGO floats drift at the surface. Some of the drifters lost their drogue after some time making their drift behavior similar to that of ARGO floats. The used drifter data set was updated for the new meta data information, where the drogue loss dates were corrected (Lumpkin et al. 2013). The different platforms have different sensitivity to the wind slip that is accounted for as explained below. The ARGO floats are corrected for the wind slip at the surface similar to the corrections applied to the undrogued drifters (Pazan and Niiler 2001) with differing coefficients A:

$u_{\text {corrected }}=u_{\text {uncorrected }}-A W_{x}$

$v_{\text {corrected }}=v_{\text {uncorrected }}-A W_{y}$,

where $W_{x}$ and $W_{y}$ are the zonal and meridional component of wind velocity (in units of $\mathrm{m} \mathrm{s}^{-1}$ ) from NCEP/NCAR Reanalysis 6-hourly winds. The coefficient $\mathrm{A}$ was set to $\mathrm{A} 1=1.14 \times 10^{-2}$ for the ARGO floats, A2 $=1.64 \times 10^{-2}$ for undrogued drifters and $\mathrm{A} 3=7 \times 10^{-4}$ for drogued drifters as in Perez et al. (2013) to account for the different response of the observational platforms to the wind induced slip. The derived velocities were then averaged on a $1^{\circ} \times 1^{\circ}$ grid of latitude and longitude with an overlap of $2^{\circ}$ in both directions to enlarge the amount of observations within the individual grid boxes.

For this study, investigating the contribution of the individual terms to the ML heat budget within the seasonal cycle, average monthly estimates of surface velocities are required. As drifters as well as ARGO floats can be captured within the vortices of tropical instability waves (TIWs), which act on intraseasonal timescales, the possible bias due to these intraseasonal phenomena needs to be eliminated. In order to derive unbiased monthly estimates required for this study the maximum amount of independent data points combining the drifter and ARGO data base is used: data of the individual drifters is available on a 6 hourly grid, which does not represent independent data. Moored observations from Perez et al. (2013) reveal a de-correlation time scale between 7 and 10 days for meridional velocity, which also agrees with the temporal resolution of the ARGO float data. Accordingly, the data of individual drifters were subsampled by averaging over 10-day periods and then combined with the ARGO data base. The use of shorter de-correlation time scales that is associated with a larger weight on drifter data relative to ARGO float data results only in minor changes in the resulting advective heat flux as long as the de-correlation time scale is larger than 1 day.

\subsubsection{SST}

To accurately determine local horizontal SST gradients required for evaluating heat advection terms (see below) a SST climatology of higher resolution compared to the one available from Reynolds and Smith $(1994)\left(1^{\circ} \times 1^{\circ}\right)$ was needed: Moum et al. (2013) described an underestimation of the meridional heat advection when using a SST climatology of $1^{\circ}$ horizontal resolution. Hence here, monthly averages of satellite SSTs from the Tropical Microwave Imager 
(TMI) onboard the Tropical Rainfall Measuring Mission (TRMM) satellite (www.ssmi.com/tmi/) were used, which are available at a $0.25^{\circ} \times 0.25^{\circ}$ horizontal resolution. A monthly-mean SST climatology was produced by averaging the monthly SST observations between 1998 and 2012 (TMI SSTs are available since December 1997).

\subsubsection{Surface heat fluxes}

The individual contributions to the net surface heat flux at the ocean's surface from the recently developed TropFlux (Praveen Kumar et al. 2012) product are considered. This recent product was especially developed for the tropical oceans and the individual fluxes are available at daily or monthly resolution from 1979 to present on a $1^{\circ} \times 1^{\circ}$ grid. Monthly values are used to build an average longterm monthly climatology of the individual surface fluxes using data between 1997 and 2012 coinciding with the period of available PIRATA observations. The resulting climatological surface fluxes of the TropFlux product are then compared to the PIRATA observations after applying the COARE algorithm (Fairall et al. 2003). Additionally, climatological long wave radiation from the daSilva et al. (1994) surface marine atlas available on a $1^{\circ} \times 1^{\circ}$ grid was used for comparison with the TropFlux product. The comparison between TropFlux and PIRATA/daSilva derived surface heat fluxes is presented in Appendix 1.

\subsubsection{Mixed layer depth}

Finally, to determine horizontal gradients of MLD (needed for the calculation of the entrainment term, see below), the ML climatology of de Boyer Montégut et al. (2004) was used for estimating the entrainment term. The long-term monthly means are only available at $2^{\circ}$ resolution in both latitude and longitude, but are interpolated on a $1^{\circ} \times 1^{\circ}$ grid to match the resolution of the other variables.

\subsection{Methodology}

To assess the relative importance of the diapycnal heat fluxes on the ML heat budget, the individual terms of the budget are estimated. The heat balance equation for the ML in the following form was first introduced by Stevenson and Niiler (1983). Since then, it has been frequently used in observational studies evaluating the individual contributions to the ML heat budget (Moisan and Niiler 1998; Wang and McPhaden 1999; Foltz et al. 2003) and reads:

$$
\begin{aligned}
& h \frac{\partial T}{\partial t}+h\left(\mathbf{v} \cdot \nabla T+\overline{\mathbf{v}^{\prime} \cdot \nabla T^{\prime}}\right)+\left(T-T_{-h}\right) w_{\text {entrain }} \\
& +\nabla \cdot \int_{-h}^{0} \widehat{\mathbf{v}} \widehat{T} d z=\frac{q_{n e t}-q_{-h}}{\rho c_{p}},
\end{aligned}
$$

where $h$ represents the thickness of the ML, and $\mathbf{v}$ and $T$ are the vertically averaged velocity and temperature in the depth range between the surface and $-h . \mathbf{v}^{\prime}$ and $T^{\prime}$ are the deviations from the temporal means and $\widehat{\mathbf{v}}$ and $\widehat{T}$ are the deviations from the vertical average. The overbar of the third term indicates temporal averaging. $w_{\text {entrain }}$ is the entrainment velocity and $T_{-h}$ is the temperature at the base of the ML. $q_{n e t}$ denotes the net surface heat flux, and $q_{-h}$ the net heat loss through the base of the ML. Here, $q_{-h}$ is determined from a combination of the penetrative shortwave radiation and the diapycnal heat flux at the base of the ML. From left to right the terms represent local heat storage, horizontal advection (divided into a mean and eddy term), entrainment, the vertical temperature/ velocity covariance (e.g. due to baroclinic flow within the ML) and the combination of net atmospheric heating and vertical turbulent diffusion at the base of the ML. The vertical temperature/velocity covariance involves the correlation of the possible departures of horizontal velocity and temperature from their vertically and temporally averaged values in the ML. Swenson and Hansen (1999) estimated the heat flux due to this term considerably smaller than the other contributions and hence this term will be neglected in the following as also described in Foltz et al. (2003).

The evaluation of the individual terms closely follows the procedures described by Foltz et al. (2003). Seasonal cycles of different variables are obtained from daily PIRATA data, averaged on every given day of the year and subsequently averaged for each month of the year. The penetrative fraction of the shortwave radiation depends on the MLD and the optical transparency of seawater. Here, it is calculated via an e-folding decay following Wang and McPhaden (1999), who parameterized shortwave radiation absorbed in the ML as $Q_{a b s}=Q_{\text {short }}\left(1-0.45 e^{-h / 25 m}\right)$. Latent and sensible heat fluxes were calculated from the PIRATA buoy data using the COARE algorithm (Fairall et al. 2003) for comparison with the TropFlux product, which uses the same algorithm (see Appendix 1). Mean horizontal advection is determined by multiplying the monthly mean velocities (calculated from the combined ARGO and drifter velocities) with climatological longterm SST gradients from the TMI satellite observations. The eddy term of horizontal advection is estimated indirectly from the residual between mean horizontal advection described above and total horizontal advection estimated as $h(\mathbf{v} \cdot \nabla T)=h\left(\frac{d T}{d t}-\frac{\partial T}{\partial t}\right)$ (Swenson and Hansen 1999). The total time derivative is obtained from drifter SSTs, whereas the local derivative is estimated from the average monthly TMI SSTs. The entrainment velocity can be expressed as $w_{\text {entrain }}=\frac{\partial h}{\partial t}+\nabla \cdot h \mathbf{v}$ (Stevenson and Niiler 1983) representing the local time derivative of the depth of the base of the ML from PIRATA temperature time series 
and a divergence term of the product of the MLD and surface velocity climatology.

MLDs were calculated from PIRATA subsurface temperature time series and taken from the MLD climatology of de Boyer Montégut et al. (2004). The climatology is built upon the temperature threshold criterion of $0.2^{\circ} \mathrm{C}$. In the study of Foltz et al. (2003) MLDs are calculated with the temperature threshold criterion of $0.5{ }^{\circ} \mathrm{C}$, but using only the profiles between 5.00 and 7.00 local time as a reference for the threshold to avoid the influence of shallow diurnal mixed layers. Different temperature thresholds $\left(0.2\right.$ and $\left.0.5^{\circ} \mathrm{C}\right)$ referenced against SSTs between 5.00 and 7.00 local time as well as the temperature gradient criterion described in Lorbacher et al. (2006) for PIRATA subsurface temperatures have been evaluated and compared to the MLDs of the climatology of de Boyer Montégut et al. (2004) at the PIRATA locations. Best agreement was found for the temperature threshold of $0.5^{\circ} \mathrm{C}$, which is therefore further used here to estimate MLDs from PIRATA subsurface temperatures.

\section{Results}

\subsection{Seasonal variability at the PIRATA sites}

Among the four considered PIRATA buoy locations, which are representative for different regions within the ACT, large seasonal variability in the background setting is observed. Common to all regions within the ACT is the strong cooling of SSTs starting around April/May (Fig. 2a). The strongest cooling is observed on the equator at $10^{\circ} \mathrm{W}$, which is sometimes referred to as the center of the ACT (Jouanno et al. 2011b). The structure of the seasonal variability of SSTs at the western $\left(23^{\circ} \mathrm{W}\right)$ and eastern $\left(0^{\circ} \mathrm{E}\right)$ edge of the ACT on the equator is very similar to $10^{\circ} \mathrm{W}$. However, the southern ACT region exhibits a slower cooling phase followed by a delayed and more rapid warming phase. Towards the end of the year SSTs recover to warm levels at all locations reaching their maximum levels in March/April again.

The seasonal cycle of net surface heat fluxes from the TropFlux product (see Appendix 1 for a comparison between TropFlux and PIRATA) varies considerably within the ACT (Fig. 2b). The seasonal variation at all locations is mainly caused by variations in the incoming solar radiation and the latent heat flux, whereas the sensible heat flux and the outgoing long-wave radiation remain rather constant throughout the year (Foltz et al. 2003; Hummels et al. 2013). However, within the equatorial region, net surface heat flux is typically positive. In the western and central part of the equatorial ACT region $\left(23^{\circ} \mathrm{W}\right.$ and $\left.10^{\circ} \mathrm{W}\right)$ the ML is warmed throughout the year by $50-100 \mathrm{~W} \mathrm{~m}^{-2}$.
Note that here the net surface heat flux is calculated with the absorbed shortwave radiation, which is corrected for the amount of heat penetrating through the ML estimated from PIRATA sub-surface temperatures. Within the eastern equatorial ACT $\left(0^{\circ} \mathrm{E}\right)$ the superposition of annual and semiannual cycles of the net surface heat fluxes leads to a net heat flux minimum from May to July when SSTs decrease. In the southern $\mathrm{ACT}$ region $\left(10^{\circ} \mathrm{S}, 10^{\circ} \mathrm{W}\right)$ a strong annual cycle of net surface heat fluxes is observed, which includes a ML warming as well as a cooling phase. At this location the cooling phase of the ML due to a change in atmospheric forcing of nearly $200 \mathrm{~W} \mathrm{~m}^{-2}$ coincides with a decline of SSTs.

MLDs are in general shallow in the eastern equatorial Atlantic due to the shoaling thermocline. Accordingly, within the equatorial ACT region MLDs decrease from west $\left(23^{\circ} \mathrm{W}\right)$ to east $\left(0^{\circ} \mathrm{E}\right)$ (Fig. $\left.2 \mathrm{c}\right)$. At all locations within the equatorial belt, MLDs exhibit a seasonal cycle with maximum MLDs of 40-50 $\mathrm{m}$ in boreal autumn and 15$20 \mathrm{~m}$ during boreal spring. Within the southern ACT region MLDs are generally larger than in the equatorial belt. In the south, the seasonal variation ranges from around $40 \mathrm{~m}$ in boreal winter/spring to maximum $80 \mathrm{~m}$ during boreal summer/autumn.

Winds in the ACT region are dominated by the westward trades (easterlies) surrounding the ITCZ, which migrates meridionally during the year. For the equatorial ACT region this migration imprints an annual signal on the wind stress magnitude with strongest winds in August, when the ITCZ is at its northernmost position (Fig. 2d). A weaker semiannual signal, which peaks in April/May and September/ October is superimposed on the dominant annual pattern yielding a double peaked structure. The southern ACT region exhibits only an annual variation in wind stress, which peaks in August, increasing the latent heat flux during this period. This increased latent heat flux contributes to the strong cooling via net surface heat fluxes in the southern ACT (Fig. 2b).

Zonal surface velocities in the equatorial ACT region, determined from a combination of ARGO float and surface drifter data, are subject to a relatively strong semi-annual cycle. This appears odd at first glance, as the wind forcing is dominated by the annual cycle with only a weak semiannual imprint. However, the semi-annual cycle in zonal velocity was explained by the presence of a resonantly forced basin mode (Cane and Moore 1981; Thierry et al. 2004; Ding et al. 2009). The current dominating the equatorial region is the northern branch of the South Equatorial Current (nSEC) (Lumpkin and Garraffo 2005; Hummels et al. 2013), (Fig. 2e). During boreal summer maximum westward velocities are observed of about $0.25-0.5 \mathrm{~m} \mathrm{~s}^{-1}$ depending on the exact location within the equatorial belt. In the central and eastern equatorial Atlantic, zonal velocities 


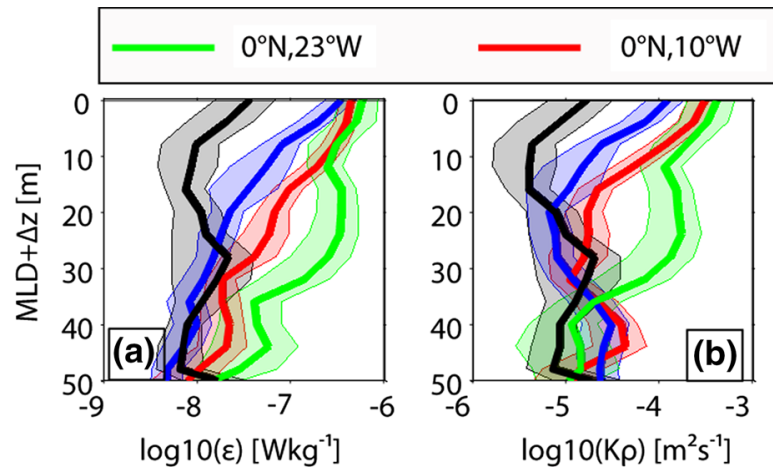

Fig. 3 Vertical profiles of turbulent parameters during summer (June/ July) for the different locations within the ACT: a dissipation rates of turbulent kinetic energy $(\varepsilon)$, b turbulent eddy diffusivities $\left(K_{\rho}\right)$, $\mathbf{c}$ vertical gradient of potential temperature $\left(\theta_{z}\right)$ and $\mathbf{d}$ diapycnal heat fluxes $\left(J_{h}\right)$. Error bars are $95 \%$ confidence limits, see Appendix 3

even reverse in sign during the seasonal cycle. Due to the vanishing Coriolis parameter at the equator, meridional velocities might be directly forced by the meridional wind component. As winds at the equator have a southerly (from south to north) component and are largest in boreal summer and fall, meridional velocities are directed in the same direction (Rhein et al. 2010). This is also consistent with the results from Perez et al. (2013), where positive (northward) meridional velocities are found at the equator at $23^{\circ} \mathrm{W}$ and $10^{\circ} \mathrm{W}$. However, their magnitude is significantly reduced compared to zonal velocities (Fig. 2f). In the southern ACT region zonal as well as meridional surface velocities are of reduced magnitude compared to the equatorial region and do not show a distinct seasonal variation. Surface velocities within this region are dominated by the Ekman flow. According to the steady trade winds (south-easterlies), the Ekman flow is directed towards the southwest throughout the year (Fig. 2e, f).

\subsection{Turbulent mixing within the ACT}

In this section, the new and unique data set of microstructure observations acquired in the central and eastern equatorial Atlantic (Hummels et al. 2013) is used to estimate the diapycnal ML heat loss directly, rather than relying on residual estimates of this quantity as has been done previously (Wang and McPhaden 1999; Foltz et al. 2003, 2013; Wade et al. 2011). The main findings relevant for this study from Hummels et al. (2013) concerning the regional and seasonal variability of turbulent mixing are summarized in the following: Turbulent dissipation rates $(\varepsilon)$ at the equator are significantly increased in the upper thermocline compared to off-equatorial locations (cf. Fig. 3a). Within the equatorial region turbulent dissipation rates in the upper thermocline are:
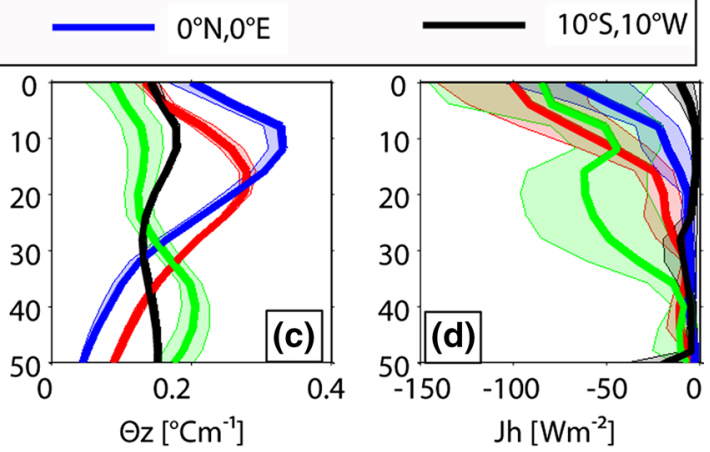

for details. Note that the depth range of the profiles shown in a-d is restricted to the upper thermocline, i.e. 0 corresponds to the ML depth and logarithmic abscissae scaling is used in panels $(\mathbf{a}, \mathbf{b})$. Note that the vertical temperature gradient is shown in (c) as it is an important constituent in the formulation of the diapycnal heat flux

1. Elevated in the western equatorial ACT region in comparison to the eastern equatorial ACT region (cf. Figure 3a);

2. Most intense mixing is observed in boreal summer in the whole equatorial $\mathrm{ACT}$ region;

Hummels et al. (2013) described a close correspondence between the seasonal and regional variability of background shear and stratification levels and ensemble mixing intensities, turbulent eddy diffusivities $\left(K_{\rho}\right)$ and diapycnal heat fluxes $\left(J_{h}\right)$ : e.g. vertical shear squared of horizontal velocities $\left(S^{2}=(\partial U / \partial z)^{2}+(\partial V / \partial z)^{2}\right)$ was found to reduce from $10^{\circ} \mathrm{W}$ towards the eastern equatorial ACT, while stratification $\left(\mathrm{N}^{2}\right)$ increased. This reduces the likelihood of shear instabilities to occur in the Gulf of Guinea and indeed turbulent parameters such as dissipation rates as well as diapycnal ML heat losses were observed to decrease in magnitude from the western equatorial region towards the east. Despite stronger zonal subsurface velocities at $23^{\circ} \mathrm{W}$ compared to $10^{\circ} \mathrm{W}$ (Brandt et al. 2011a), shear levels are reduced at $23^{\circ} \mathrm{W}$ compared to $10^{\circ} \mathrm{W}$ (Jouanno et al. 2011b). This can be explained by the shoaling of the EUC towards the east, which limits the depth range of opposite flowing currents, westwards at the surface and eastwards in the subsurface. The highest shear levels in the central equatorial ACT region correspond to highest mixing activity. Within the southern ACT, shear levels were significantly reduced due to the lack of strong current features and turbulent mixing was found to be low. The relation between background shear and stratification conditions and turbulent mixing activity will be further analyzed later in this study.

According to the described variability in shear levels, average summer dissipation rates below the ML range from $3.5 \times 10^{-7} \mathrm{~W} \mathrm{~kg}^{-1}$ in the eastern to $7 \times 10^{-7} \mathrm{~W} \mathrm{~kg}^{-1}$ in the western equatorial ACT (Fig. 3a). In the southern ACT 
dissipation rates below the ML do not exceed $5 \times 10^{-8}$ $\mathrm{W} \mathrm{kg}^{-1}$. At a depth of $50 \mathrm{~m}$ below the ML, equatorial dissipation rates have dropped by about one order of magnitude (Fig. 3a). Inferred eddy diffusivities (Sect. 2.1.1) just below the ML range from $1.2 \times 10^{-4} \mathrm{~m}^{2} \mathrm{~s}^{-1}$ in the eastern to $7 \times 10^{-4} \mathrm{~m}^{2} \mathrm{~s}^{-1}$ in the western equatorial ACT, while values in the southern ACT only reach $1.6 \times 10^{-5} \mathrm{~m}^{2} \mathrm{~s}^{-1}$ at maximum. The magnitude and vertical structure of the observed turbulent parameters agrees rather well with those inferred from microstructure measurement programs carried out in the central equatorial Pacific (Gregg et al. 1985; Peters et al. 1988; Moum et al. 1989; Lien et al. 1995). However, in comparison to the central equatorial Pacific, Hummels et al. (2013) report for the equatorial ACT region a reduction in the night time enhancement of turbulence, which is referred to as deep cycle turbulence (Moum and Caldwell 1985). Nevertheless, to avoid possible biases due to an unevenly distributed sampling time of profiles during the day, mean profiles of turbulent parameters are derived here by separately averaging measurements collected during the day (08:00-20:00) and night (20.00-08:00) before calculating mean profiles. The average of the mean day and mean night profiles are then further incorporated into the ML heat budgets.

In order to obtain the turbulent contribution of diapycnal heat fluxes to the ML heat budget, the transition zone between the base of the ML and the stratified region below has to be accurately resolved. In the equatorial Atlantic as well as in the Pacific, profiles of the diapycnal heat flux are highly divergent below the ML. Maximum values are found at the base of the ML that rapidly decrease in deeper layers (Fig. 3d; Lien et al. 2008). In most of the mean profiles (Fig. 3d), diapycnal heat flux at $20 \mathrm{~m}$ below the ML is significantly reduced. Hence, the amount of heat being extracted from the ML into the interior ocean is characterized by the diapycnal heat flux in a rather narrow layer. Here, diapycnal ML heat loss is determined by averaging the diapycnal heat flux profiles in the interval MLD $+5 \mathrm{~m}$ to MLD $+15 \mathrm{~m}$. The reason to use this averaging interval is to ensure values from within the ML to be excluded from the estimate as the method from Osborn (1980), which we use here, is only valid in stratified sheared flow. Due to strong variability in stratification within a few meters below the ML, and due to the fact that stratification for the Osborn parameterization needs to be calculated over a larger length scale than turbulent overturns (that can be as much as several meters due to the strong mixing there), we decided to use this depth interval. Due to the elevated vertical divergence of the heat flux profiles, this approach leads to estimates of diapycnal heat loss of the ML being biased low. The error of this approach can be estimated from the average heat flux profiles by extrapolating from MLD $+10 \mathrm{~m}$ to the MLD. The extrapolation needs to be performed as the diapycnal heat flux obtained directly below the ML with the Osborn method can not be considered reliable as explained above. Overall, the diapycnal heat flux reduces by about $30 \%$ at MLD $+10 \mathrm{~m}$ compared to the value directly below the ML.

Note that the MLD from vertically high resolved CTD profiles was generally calculated using the temperature threshold criterion with $\Delta \mathrm{T}=0.2{ }^{\circ} \mathrm{C}$ compared to the SST. Heat flux profiles and inferred diapycnal ML heat losses were calculated separately for every station. Subsequently, these station averaged profiles of the different sections of an individual cruise between $2^{\circ} \mathrm{S}$ and $1.5^{\circ} \mathrm{N}$ were averaged in day and night ensemble (see above) to obtain a single estimate that was taken as representative for diapycnal heat loss of the ML for the month in which the measurements were collected. Uncertainties for each individual estimate were calculated using Gaussian error propagation as described in Hummels et al. (2013).

\subsection{Mixed layer heat budget}

In the following, the contributions to the ML heat budget derived from PIRATA observations, climatological data sets as well as microstructure observations are combined at the four different locations within the ACT. Note that the individual contributions to the $\mathrm{ML}$ heat budget at $0^{\circ} \mathrm{N}$, $10^{\circ} \mathrm{W}$ were already analyzed in Hummels et al. (2013). However, to achieve a consistent comparison between heat budgets at the different PIRATA locations, the analysis of the heat budget at $0^{\circ} \mathrm{N}, 10^{\circ} \mathrm{W}$ is repeated here partly using different data products (concerning the surface velocities and the net surface heat fluxes) compared to Hummels et al. (2013).

Several modeling as well as observational studies have addressed the ML heat budget in the eastern equatorial Atlantic previously (Foltz et al. 2003; Peter et al. 2006; Jouanno et al. 2011b; Wade et al. 2011; Hummels et al. 2013). Among these studies, the definition of high and low frequency advection terms, referred to as mean and eddy advection here (Sect. 2.4), varied. Hence, in order to compare the results amongst the different studies it has to be clarified which oceanic processes are attributed to the different terms. As has been pointed out in the tropical Pacific analysis by Wang and McPhaden (1999) processes reflected in the eddy advection term close to the equator, particularly in the meridional component, significantly depend on the latitudinal averaging interval over which the heat budget analysis is performed. For local heat budgets or budgets performed for small regions around the equator (i.e. $\pm 2^{\circ}$ in latitude), the eddy advection warms the ML as the effect of TIWs laterally advecting warm waters are explicitly resolved (Foltz et al. 2003; Jochum and Murtugudde 2006; Peter et al. 2006). When budgets are performed 

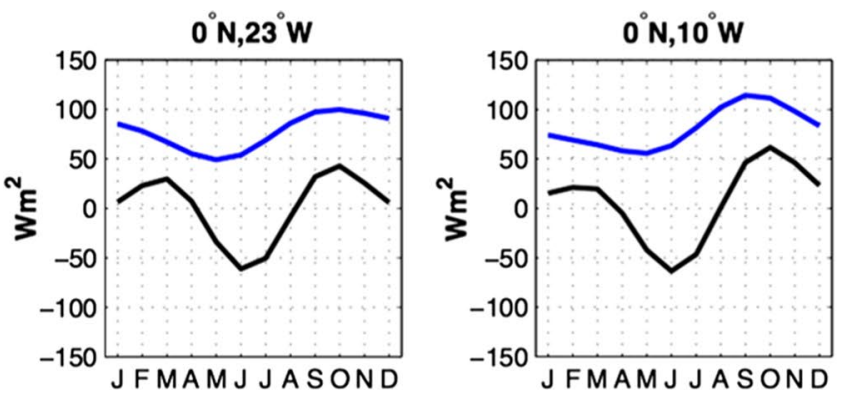

Fig. 4 Comparison of the net surface heat flux (absorbed shortwave radiation (corrected for the amount of shortwave radiation penetrating through the ML) + latent heat flux + sensible heat flux + outgoing

over a larger meridional extent, eddy advection will cool the ML as TIW contributions are averaged out and the Ekman divergence dominates. This study focuses on local heat budgets at the locations of the PIRATA buoys and thus requires evaluating the eddy heat fluxes as local as possible. Opposing this minimum regional extent requirement is the accuracy of velocity and SST gradient data, for which the statistical reliability of the individual variables increases when they are averaged over larger meridional intervals. As a compromise between locality and statistical reliability, a $2^{\circ}$ latitudinal and longitudinal interval is used to evaluate mean and eddy advection terms. In doing so, the warming effect of TIWs will dominate the eddy advection term.

When the net surface heat flux is compared to the observed heat storage, large negative residuals are evident in the western $\left(23^{\circ} \mathrm{W}\right)$ and central $\left(10^{\circ} \mathrm{W}\right)$ equatorial $\mathrm{ACT}$ and a reduced residual in the eastern $\left(0^{\circ} \mathrm{E}\right)$ equatorial ACT (Figs. 4 , 5). In contrast, within the southern ACT region, SST variability during ACT development can virtually be explained by the variability in net atmospheric forcing. Hence, the residuals in the equatorial region need to be explained by different oceanic processes, which probably also vary in their relative contribution within the seasonal cycle.

In the following, the respective contributions of atmosphere and ocean processes to the warming and cooling of the ML during the absence, development and mature phase of the ACT will be discussed. As the focus of this study is on the seasonal variability of the individual contributions to the ML heat budget, annual and semi-annual harmonics were fitted to the individual terms (except for the diapycnal ML heat loss) before illustration (Fig. 5).

\section{$3.40^{\circ} \mathrm{N}, 23^{\circ} \mathrm{W}$}

At the western edge of the $\mathrm{ACT}\left(23^{\circ} \mathrm{W}\right)$ in the central equatorial Atlantic, the ML is warmed by net atmospheric forcing (Fig. 2b, 5a) and by eddy heat advection. In the central equatorial Atlantic eddy heat advection is predominately controlled by TIWs (Wang and McPhaden 1999; Jochum
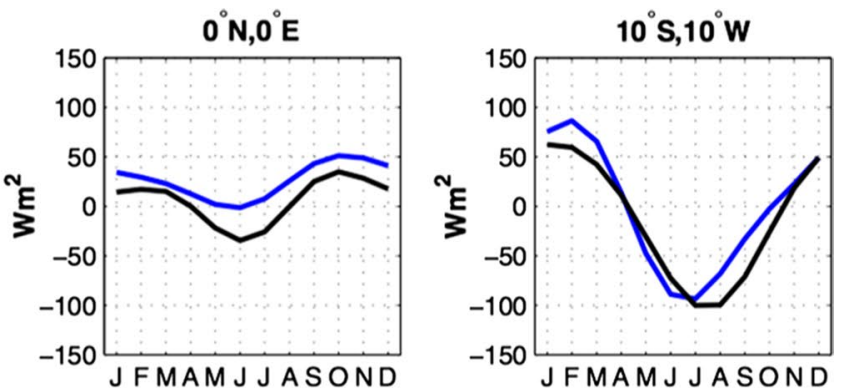

longwave radiation) in blue and the observed heat storage in black for the four different locations within the ACT

and Murtugudde 2006; Peter et al. 2006). TIW activity here was reported enhanced in the beginning of the year, in boreal summer and autumn (Bunge et al. 2007; von Schuckmann et al. 2008), which agrees with periods of elevated eddy advection in this analysis (Fig. 5a). Cooling of the ML is achieved by subsurface processes (diapycnal mixing and entrainment) as well as mean heat advection (Fig. 5a).

During the absence of the ACT (January to April), the ML balance is dominated by net atmospheric forcing and eddy heat advection, the latter contributing to a warming of up to $50 \mathrm{~W} \mathrm{~m}^{-2}$ in January. During March and April, when the tropical Atlantic is uniformly warm and the meridional gradient of SST is very weak, the eddy heat advection reduces to zero.

During the development phase of the ACT (May to August) the net surface heat flux increases, mainly due to increased incoming solar radiation, which counteracts the observed cooling of SSTs. Eddy advection dominated by the effect of TIWs as discussed above contributes to the warming of the ML. However, there is a strong increase in ML cooling from zonal heat advection $\left(60 \mathrm{~W} \mathrm{~m}^{-2}\right)$ and entrainment $\left(25 \mathrm{~W} \mathrm{~m}^{-2}\right)$ during this phase. The elevated zonal advection term is due to the persistent westward flow (Fig. 2e) advecting cooler surface waters from the central ACT towards $23^{\circ} \mathrm{W}$. In addition, elevated diapycnal heat loss at and below the ML further contributes to cool the ML: the two independent estimates for June from 2006 and 2011, $58 \mathrm{~W} \mathrm{~m}^{-2}$ (M68/2) and $54 \mathrm{~W} \mathrm{~m}^{-2}$ (MSM18/2) respectively, agree well. The cooling dominated by the diapycnal heat flux and zonal heat advection is strong enough to reduce SSTs despite the warming due to net surface heat fluxes and eddy advection.

Within the mature phase of the ACT (August to the end of the year) the net surface heat flux significantly warms the ML. Eddy advection still contributes significantly $\left(50 \mathrm{~W} \mathrm{~m}^{-2}\right)$ to the warming. Cooling provided by zonal heat advection decreases at the beginning of the mature phase, due to the reduction in surface velocities associated 

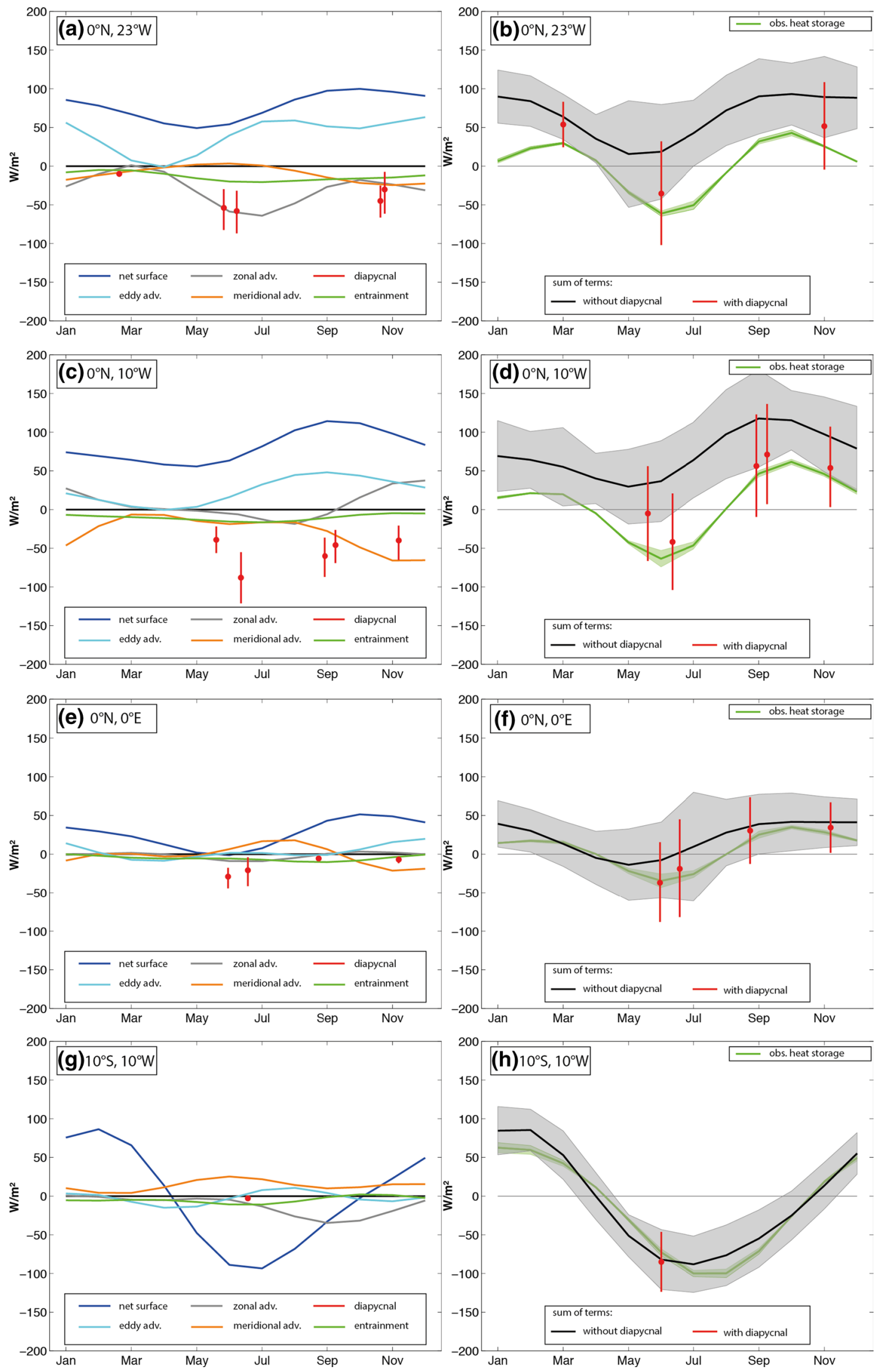
4Fig. 5 Left panels: Individual contributions to the ML heat budget at the different locations within the ACT (color code explained in the legend). Vertical red lines denote $95 \%$ confidence limits for the diapycnal ML heat loss. Right panels: Sum of the individual contributions without (black) and with (red) the diapycnal ML heat loss; observed heat storage is in green. Grey shading denotes $95 \%$ confidence limits for the sum of terms excluding the diapycnal ML heat loss, red vertical lines denote $95 \%$ confidence limits including the diapycnal ML heat loss; see Appendix 3 for details

with the nSEC (Fig. 2e). Towards the end of the year zonal heat advection re-intensifies in accordance with reintensified zonal velocities associated with the nSEC. The diapycnal heat flux during this period is still large. The two independent estimates for November from 2009 and 2012 yielded $45 \mathrm{~W} \mathrm{~m}^{-2}$ (MSM22) and $30 \mathrm{~W} \mathrm{~m}^{-2}$ (M80/1) respectively. The meridional heat advection increases within this phase due to increasing meridional velocities (Fig. 2f) and increasing MLD (Fig. 2c). Entrainment still contributes a cooling of about $15 \mathrm{~W} \mathrm{~m}^{-2}$ during this phase. However, the gradual overall reduction of the cooling terms lead to a gradual increase in SSTs towards the end of the year.

Comparison of the sum of the individual terms contributing to the ML heat budget and the observed heat storage reveals a large residual of $30-100 \mathrm{~W} \mathrm{~m}^{-2}$ throughout the year, if the contribution of the diapycnal heat flux is omitted (Fig. 5b). This was also reported in the recent study of Foltz et al. (2013). Similar residuals (around $80 \mathrm{~W} \mathrm{~m}^{-2}$ ) have been reported in previous observational studies from the central equatorial Pacific (Wang and McPhaden 1999) as well as from the western equatorial ACT (Wade et al. 2011), where the diapycnal contribution could not be estimated. Including the resolved seasonal variability of the diapycnal heat flux into the sum of terms reduces the residual in boreal summer and November by more than a factor of 2 and closes the heat budget at least within the uncertainties (Fig. 5b). The diapycnal ML heat loss together with mean zonal advection are identified as the dominant contribution to the cooling of SSTs during ACT development at $0^{\circ} \mathrm{N}, 23^{\circ} \mathrm{W}$.

\subsection{1 $0^{\circ} \mathrm{N}, 10^{\circ} \mathrm{W}$}

In the center of the $\mathrm{ACT}\left(10^{\circ} \mathrm{W}\right)$ the $\mathrm{ML}$ is warmed by the atmosphere and eddy advection as was observed for $23^{\circ} \mathrm{W}$. The ML is cooled by subsurface processes (diapycnal mixing and entrainment) as well as the meridional heat advection (Fig. 5c). Zonal heat advection at this site is significantly reduced in magnitude compared to the western edge of the ACT $\left(23^{\circ} \mathrm{W}\right)$. Although westward surface velocities associated with the nSEC are also intensified at this location (Fig. 2e), the low zonal temperature gradient in the center of the ACT and shallow MLDs lead to reduced zonal heat advection compared to $23^{\circ} \mathrm{W}$.

During the absence of the ACT (January to April) the ML heat budget at $10^{\circ} \mathrm{W}$ is dominated by net atmospheric forcing. The largest oceanic contribution is the meridional heat advection cooling the ML, which balances the warming via zonal heat advection and eddy advection. The meridional velocity is as explained previously a direct response to the meridional wind forcing. Although elevated ML cooling due to diapycnal heat fluxes is anticipated during this period, this study lacks observational support for this hypothesis.

Within the development phase of the ACT (May to August), the net heat flux from the atmosphere increases due to the reduction in latent heat flux due to reduced wind speed and an increase in the incoming solar radiation (Figs. 2b, 5c). Additional warming is provided by the eddy advection due to TIWs, similar as discussed for $23^{\circ} \mathrm{W}$. However, strong subsurface cooling leads, despite these warming terms, to a cooling of the ML. The relative constitution of the subsurface cooling at this location differs from the observations at $23^{\circ} \mathrm{W}$ : Zonal heat advection is significantly reduced compared to $23^{\circ} \mathrm{W}$, whereas entrainment is of similar magnitude cooling the $\mathrm{ML}$ at a rate of about $20 \mathrm{~W} \mathrm{~m}^{-2}$, which agrees with the results obtained by Rhein et al. (2010). The striking difference is the clear dominance of the diapycnal ML heat loss of up to $90 \mathrm{~W} \mathrm{~m}^{-2}$ over the other oceanic cooling contributions. As detailed in Hummels et al. (2013) elevated vertical shear of horizontal velocities increases the occurrence of shear instabilities leading to the elevated diapycnal heat fluxes during this phase.

During the mature phase of the ACT (August towards the end of the year) atmospheric warming stays on a rather high level. The cooling due to the diapycnal heat flux is still of considerable magnitude, but decreasing. The dominance of the diapycnal heat flux within the subsurface cooling terms reduces in favor of the meridional heat advection, which reaches $60 \mathrm{~W} \mathrm{~m}^{-2}$ towards the end of the year. This increase in meridional heat advection is due to enhanced meridional velocities presumably caused by increased southerly winds, temperature gradients and MLDs (Fig. 2). The warming effect of the eddy advection reduces during the mature phase and is accompanied by the zonal heat advection actually warming the ML towards the end of the year. This is due to the changing sign of the zonal velocity (the reversal of the nSEC between August and October; Fig. 2e) and the subsequent sign change for the zonal temperature gradient occurring in November and December (not shown). The gradual reduction in the total subsurface cooling leads to a gradual increase in SSTs during this phase. 
Comparison of the sum of the individual terms of the ML heat budget to the observed heat storage reveals a large residual of up to $110 \mathrm{~W} \mathrm{~m}^{-2}$ when omitting the contribution of the diapycnal heat flux during boreal summer and autumn (Fig. 5d). This was already reported by Foltz et al. (2003), who performed a similar study at this location. Consideration of the diapycnal heat flux as a contributing term yields in a closure of the budget within the uncertainties from June to November. However, as further described below, ML cooling due to diapycnal mixing is likely to contribute to the ML budget also during the absence of the ACT.

\subsection{2 $0^{\circ} \mathrm{N}, 0^{\circ} \mathrm{E}$}

At the eastern edge of the ACT $\left(0^{\circ} \mathrm{E}\right)$ the ML is mainly warmed by the net atmospheric forcing and cooled by the diapycnal heat flux (Fig. 5e). The other oceanic contributions do not exceed $20 \mathrm{~W} \mathrm{~m}^{-2}$ throughout the year. Zonal heat advection at this location is negligible throughout the year due to reduced zonal temperature gradients and MLDs (Figs. 1, 2c), whereas entrainment acts to slightly cool the ML throughout the year, similar to what has been observed at $10^{\circ} \mathrm{W}$. However, as pointed out above the net surface heat flux is significantly reduced in the eastern, equatorial ACT region compared to the more western and central locations $\left(23^{\circ} \mathrm{W}, 10^{\circ} \mathrm{W}\right.$, Figs. $\left.2 \mathrm{~b}, 4\right)$. Accordingly, less subsurface cooling is required to decrease SSTs at this location.

During the absence of the ACT (January to April) in the beginning of the year the ML heat budget is determined by net atmospheric forcing and oceanic contributions do not exceed $10 \mathrm{~W} \mathrm{~m}^{-2}$.

Incoming solar radiation reduces during ACT development (May to August) while the latent heat flux slightly increases, which leads to the reduction in net surface heat fluxes during this period. Concurrently, the diapycnal heat flux as inferred from microstructure observations during June 2006 and 2007 increases to its maximum value at this location of 21 and $29 \mathrm{~W} \mathrm{~m}^{-2}$ respectively and dominates the subsurface cooling (Fig. 5e). Note that at this location the seasonal variability of the diapycnal heat flux was composed from available estimates at $0^{\circ} \mathrm{N}, 0^{\circ} \mathrm{E}$ as well as around $0^{\circ} \mathrm{N}, 2^{\circ} \mathrm{E}$. MLDs are observed extremely shallow at this longitude (Fig. 2c). Hence, the additional subsurface cooling by diapycnal mixing, which superimposes on the reduced net surface heat flux, is sufficient for the strong decrease in SSTs. Eddy advection is negligible during this phase. At this longitude within the Gulf of Guinea TIWs have not been detected. Instead, Athie and Marin (2008) as well as the numerical simulation of Jouanno et al. (2013) suggest intraseasonal variability in the Gulf of Guinea dominated by wind-forced Yanai waves having long zonal wavelengths and a period between 10 and 20 days. From our analysis it seems that the effect of these waves with long zonal wavelengths on the eddy advection is significantly reduced compared to the effect of TIWs in the western equatorial ACT. Nevertheless, they might contribute to enhance vertical shear of horizontal velocity and thereby favor diapycnal mixing at this location as suggested by Jouanno et al. (2013).

During the mature phase of the ACT (August to the end of the year), a similar evolution towards the end of the year is observed as at $10^{\circ} \mathrm{W}$ on the equator. Net surface heat fluxes increase due to the increase in the incoming solar radiation. Meridional and eddy heat advection both contribute about $20 \mathrm{~W} \mathrm{~m}^{-2}$ during this phase but with opposite sign. The cooling by the diapycnal heat flux reduces, which leads together with the increased warming by the atmosphere, to the retraction of the ACT towards the end of the year.

Comparison of the sum of individual terms to the ML heat budget and the observed heat storage reveals a residual of up to $30 \mathrm{~W} \mathrm{~m}^{-2}$ when omitting the contribution of the diapycnal heat flux (Fig. 5f), which is within the uncertainties at this location. However, if the diapycnal heat flux is included, the residual reduces minimum by a factor of 2 (Fig. 5f). Even if reduced in magnitude compared to the western and central equatorial region, the diapycnal heat flux provides the largest subsurface cooling term within the development phase of the ACT and hence seems to supply the essential contribution to cool SSTs.

No detailed observational study of the ML heat budget as far east as $0^{\circ} \mathrm{E}$ in the Gulf of Guinea has been published so far. Wade et al. (2011) determined the individual terms of the ML heat budget for considerable larger regions (about $5^{\circ}$ latitude and $9^{\circ}$ longitude). Their box 5, representative for a region including $0^{\circ} \mathrm{N}, 0^{\circ} \mathrm{E}$, shows a considerable larger residual term of maximum $80 \mathrm{~W} \mathrm{~m}^{-2}$ during ACT development, which they associated with the diapycnal heat flux. Note, though that their box 5 extends until $6^{\circ} \mathrm{W}$, where the diapycnal heat flux may still be elevated compared to $0^{\circ} \mathrm{E}$. In addition, their estimate of the net surface heat flux within this box ranges from 50 to $120 \mathrm{~W} \mathrm{~m}^{-2}$ and is above our estimates at $0^{\circ} \mathrm{N}, 0^{\circ} \mathrm{E}$ especially during ACT development (Fig. 2b). Thus, for their study a larger cooling by oceanic processes is required to match the observed heat storage.

\subsection{3 $10^{\circ} \mathrm{S}, 10^{\circ} \mathrm{W}$}

Investigation of the background setting at the different PIRATA sites already revealed fundamental differences between the equatorial and the southern ACT region (Fig. 2). The net surface heat flux actually cools the ML during $\mathrm{ACT}$ development in contrast to the equatorial $\mathrm{ACT}$ region, where net atmospheric warming is observed 
throughout the year and at all locations. In general, surface velocities are weaker at this location compared to the equatorial region (Fig. 2e, f) and are not associated with distinct current features, but with the Ekman flow. Meridional heat advection tends to warm the ML at this location, while entrainment, zonal advection and eddy advection mostly cool the ML.

During the absence of the ACT (January to April) the increase in ML heat storage is balanced by net atmospheric fluxes, warming the ML (Fig. 5g).

During the development of the ACT (May and August) net surface heat fluxes significantly cool the ML by up to $90 \mathrm{~W} \mathrm{~m}^{-2}$ (Figs. 2b, 5g) due to the increase of the latent heat flux associated with increased winds as well as a reduction in the incoming solar radiation (Figs. $2 \mathrm{~d}, 5 \mathrm{~g}$ ). Surface currents associated with the Ekman flow are directed towards the southwest. Meridional advection contributes to warm the ML during this period due to the southward advection of warmer waters from the north (see Fig. 1). The other advection terms as well as entrainment are rather small during the development phase of the ACT. Zonal heat advection is small due to the lack of a significant zonal temperature gradient (not shown). The diapycnal heat flux inferred from microstructure observations during June 2006 provides a negligible contribution to the cooling (Fig. 5g). Thus, the cooling of the ML and hence SSTs during ACT development at this location is dominated by the net atmospheric forcing. Hence, the deepening of the ML from April to August can not be associated with mechanical mixing, but must be due to an increase in wind stress curl or surface buoyancy flux.

During the mature phase of the ACT (August to the end of the year) the net surface heat flux increases and gradually warms the ML again. This is due to the increase in incoming solar radiation and a reduction of the latent heat flux due to decreasing winds. The diapycnal heat flux has not been estimated at this location during this phase in the seasonal cycle. However, highest mixing activity throughout the equatorial ACT was observed in boreal summer (Hummels et al. 2013), when vertical shear of horizontal velocities is strong. As the vertical shear at this location is in general rather low due to the lack of strong current features, it seems unlikely that this term gives an important contribution to the ML heat budget during this phase.

The sum of contributing terms closely follows the evolution of the observed heat storage at this location (Fig. 5h). The residual is negligible throughout the year in agreement with the previous estimates of Foltz et al. (2003). This agrees with the fact that the diapycnal heat flux at this location was estimated rather low during the main mixing season of the equatorial ACT (Figs. 3, 5g). The decrease in SSTs at this location during ACT development is governed by the net atmospheric forcing.

\section{Summary and discussion}

A unique multi-cruise microstructure data set, observations from the PIRATA buoy network as well as climatological data sets are used to investigate the individual contributions to the seasonal ML heat budget at four different locations within the ACT region with a special focus on the role of the diapycnal heat flux. The ML budgets within different phases of the seasonal cycle associated with the absence, development and mature phase of the ACT are described. Microstructure observations allowed estimating the contribution of the diapycnal heat flux within the entire ACT region directly and not as a residual as has been done previously (Wang and McPhaden 1999; Foltz et al. 2003, 2013; Wade et al. 2011). Here, the heat budgets are presented for four PIRATA buoy sites at $0^{\circ} \mathrm{N}, 23^{\circ} \mathrm{W} ; 0^{\circ} \mathrm{N}, 10^{\circ} \mathrm{W} ; 0^{\circ} \mathrm{N}$, $0^{\circ} \mathrm{E}$ and $10^{\circ} \mathrm{S}, 10^{\circ} \mathrm{W}$ thus extending the work of Hummels et al. (2013) focusing on the heat budget at $0^{\circ} \mathrm{N}, 10^{\circ} \mathrm{W}$. The major result is that the diapycnal heat flux is a dominant cooling term for the ML heat budget in the entire equatorial Atlantic during ACT development. Towards the eastern equatorial ACT region, the discrepancy between the net surface heat flux and the observed heat storage diminishes. Likewise the magnitude of diapycnal heat flux is reduced from the western, equatorial ACT towards the east in observations (Hummels et al. 2013) and models (Jouanno et al. 2011b). However, even in the eastern equatorial ACT it was found to be the largest contribution to ML cooling.

The dominance of the diapycnal ML heat loss within the entire equatorial region has been suggested from modeling studies (Peter et al. 2006; Jouanno et al. 2011b), but up to now was only assessed from direct observations for $0^{\circ} \mathrm{N}$, $10^{\circ} \mathrm{W}$ (Hummels et al. 2013). Note that the results for $0^{\circ} \mathrm{N}$, $10^{\circ} \mathrm{W}$ presented here are essentially the same as in Hummels et al. (2013) although different data sets are used for the surface velocities and the net surface heat fluxes. This points towards the fact that the obtained results concerning the individual contributions at this location are rather robust. Outside of the equatorial region, the variability of ML heat content within the ACT is set by net atmospheric forcing and horizontal advection.

The ML heat budget during the development of the $A C T$ from May to August in the equatorial ACT region consists of the warming by net atmospheric fluxes and eddy advection and cooling by subsurface processes and horizontal advection. The cooling is dominated by the diapycnal heat flux at the base of the ML within the entire equatorial ACT. Eddy advection, which is associated with the lateral advection of heat by intraseasonal waves, moderates the cooling within the western and central equatorial ACT. Within the southern ACT region the cooling of SSTs during ACT development is driven by net atmospheric forcing. 
During the mature phase of the ACT (August to the end of the year) net atmospheric forcing increases throughout the ACT region. Additional warming by eddy advection is still present. In the equatorial belt the cooling by the diapycnal heat flux decreases, while meridional heat advection becomes more important in cooling SST towards the end of the year.

During the absence of the ACT (January to April), the increase in ML heat content at all locations within the ACT is dominated by net atmospheric forcing. The role of diapycnal heat fluxes during this period is hardly resolved from the multi-cruise data set. This will be further discussed below.

In general, the observed heat storage can be explained by the sum of terms, if the diapycnal heat flux is included. However, residuals between the sum of contributing terms remain especially within the western equatorial ACT at $0^{\circ} \mathrm{N}, 23^{\circ} \mathrm{W}$. In addition, the uncertainties attributed to the sum of contributing terms are rather large. It should be noted though that here the $95 \%$ confidence limits were presented, while in other studies only the standard error is considered. In the study of Foltz et al. (2003), the residual excluding the diapycnal ML heat loss at $23^{\circ} \mathrm{W}$ on the equator is of maximum $50 \mathrm{~W} \mathrm{~m}^{-2}$ and only present during the first half of the year. In a more recent study Foltz et al. (2013) revised this estimate using another surface velocity product. The differences between Foltz et al. (2003) and the results presented here can be attributed to extremely large zonal advection on the order of about $120 \mathrm{~W} \mathrm{~m}^{-2}$ during June-August and extremely low eddy advection from October to December, which reduce the residual in Foltz et al. (2003) during the second half of the year. Hence, the use of other surface velocity climatologies can lead to different results for the heat advection terms. This is also illustrated in Appendix 2 and demonstrates the necessity for improved surface velocity fields in order to get reliable estimates for the heat advection terms and their effect on the ML heat budget.

Unfortunately, and due to the scheduling of the microstructure measurement program the variability of the diapycnal heat flux during the absence of the ACT is not adequately resolved. However, Hummels et al. (2013) described a close agreement of the variability in the magnitude of turbulent parameters and the variability of large scale shear and stratification levels. Due to this good correspondence of vertical shear of horizontal velocities $\left(S^{2}\right)$ and stratification $\left(N^{2}\right)$ and the observed mixing intensities below the ML in the ACT region, Hummels (2012) proposed a simple relation of the form $\varepsilon=a \cdot R i^{b}$ in order to estimate the seasonal variability of dissipation rates from observations of shear and stratification only. Here $R i=N^{2} / S^{2}$ is the gradient Richardson number. The coefficients $\mathrm{a}$ and $\mathrm{b}$ were best fit to all available cruise data for the equatorial ACT region directly below the ML (MLD $+5 \mathrm{~m}-\mathrm{MLD}+20 \mathrm{~m}$ ), which resulted in $\mathrm{a}=4 \times 10^{-8}$ and $\mathrm{b}=-1.2$. To obtain this fit, shear was calculated from horizontal velocities observed with the vessel mounted ADCPs, which had a bin size of $8 \mathrm{~m}$. This simple relation seemed to provide reasonable results in terms of magnitude and seasonal variation of the dissipation rates and further inferred diapycnal ML heat losses when applied to independent shear and stratification observations.

Independent observations of stratification were estimated from the subsurface measurements of temperature and salinity at fixed depths at the PIRATA buoys at $10^{\circ} \mathrm{W}$ and $23^{\circ} \mathrm{W}$ on the equator. Vertical shear of horizontal velocity was obtained from ADCPs moored in the proximity of the PIRATA buoy locations. Using the above mixing parameterization, the diapycnal ML heat loss on the equator at $23^{\circ} \mathrm{W}$ ranges on average between $22 \mathrm{~W} \mathrm{~m}^{-2}$ at the beginning of the year and $45 \mathrm{~W} \mathrm{~m}^{-2}$ during early summer (Fig. 6a). Here only data of 2002 and 2009-2012 were used, as within these years shear and stratification directly below the ML were adequately resolved. Maximum summer heat losses due to diapycnal mixing within the individual years from this method range between 33 and $67 \mathrm{~W} \mathrm{~m}^{-2}$, which covers the range estimated directly from shipboard microstructure observations in summer $\left(58\right.$ and $\left.54 \mathrm{~W} \mathrm{~m}^{-2}\right)$. Similar good correspondence is found at $10^{\circ} \mathrm{W}$ on the equator, where on average the parameterized diapycnal heat flux ranges between 40 and $65 \mathrm{~W} \mathrm{~m}^{-2}$, whereas individual summer maxima range between 70 and $80 \mathrm{~W} \mathrm{~m}^{-2}$ compared to the maximum $90 \mathrm{~W} \mathrm{~m}^{-2}$ inferred from direct microstructure observations. Hence, this additional analysis tends to support the seasonal estimates obtained with the direct microstructure observations and could provide an estimate of the entire seasonal cycle of the diapycnal ML heat loss. In addition, the parameterized diapycnal ML heat losses suggest that even during the absence of the ACT the diapycnal ML heat loss is among the largest cooling terms in the western equatorial ACT. Incorporating these parameterized seasonal cycles of the diapycnal ML heat loss into the equatorial $\mathrm{ML}$ balances at $23^{\circ} \mathrm{W}$ and $10^{\circ} \mathrm{W}$ would lead to the closure of the ML heat budgets for the entire seasonal cycle within the uncertainties.

Despite the consistent results mentioned above further assessment of the magnitude and variability of the diapycnal heat flux via parameterization schemes is required. To fulfill this task, long term observations of turbulence and background flow and stratification parameters are needed. This could be accomplished either with moored microstructure observations (e.g. Chi-Pods, Moum et al. 2013) or by gliders mounted with microstructure probes profiling near subsurface ADCP moorings.

This study contributes to improve the understanding of the variability of SSTs in the eastern equatorial Atlantic. 

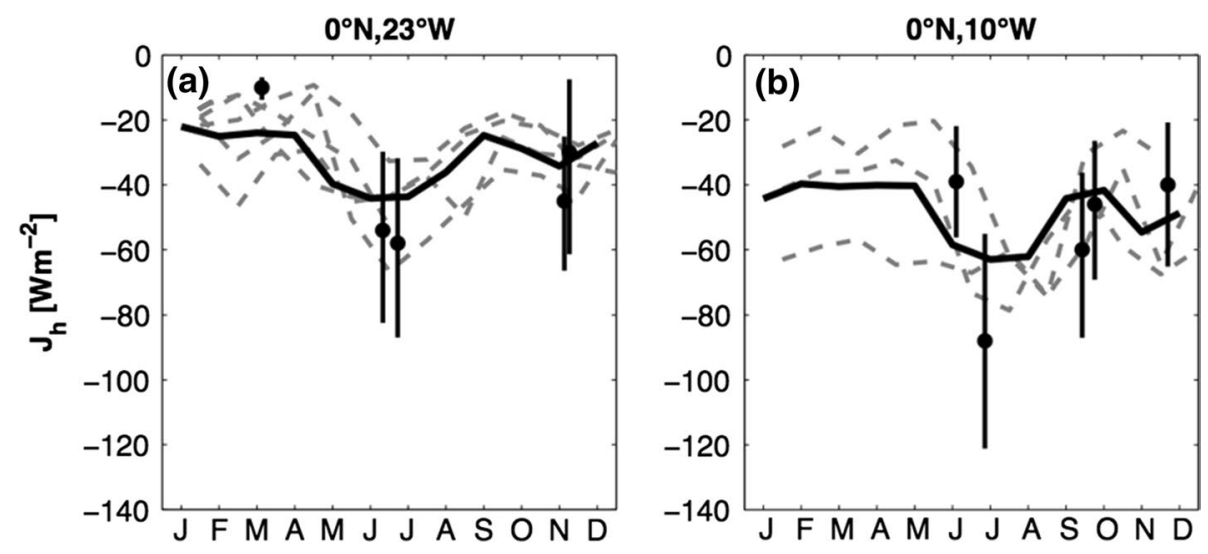

Fig. 6 Monthly averages of diapycnal ML heat loss estimated from shear and stratification observations at the PIRATA buoy sites $0^{\circ} \mathrm{N}$, $23^{\circ} \mathrm{W}$ (a) and $0^{\circ} \mathrm{N}, 10^{\circ} \mathrm{W}$ (b) (heavy black lines averaged over the years 2002 and 2009-2012 for (a) and 2006-2007 and 2009 for (b)) and monthly averages of the individual years (dashed grey lines). Black circles mark the diapycnal ML heat loss estimated from microstructure observations together with their confidence limits as presented in Fig. 5a, c respectively
The dominant contribution of the diapycnal heat flux to the ML heat budget within the equatorial ACT points out the importance of its correct representation in numerical simulations in order to improve biases in SSTs, which are of crucial relevance to reliable climate predictions.

Acknowledgements The authors thank Bernard Bourlés for the cooperation during the EGEE field campaign. We also want to thank the crews of the EGEE campaigns, R/V Meteor and Maria S. Merian as well as our technical group for their help with the field work. Financial support for this study was provided by the Deutsche Forschungsgemeinschaft as part of the Emmy Noether Program (RH and MD, grant DE1369/1-1), the PREFACE Project (grant 603521), the European Union 7th Framework Programme (FP7 2007-2013) GROOM Project (MS, grant 284321), the Sonderforschungsbereich 754 "Climate-Biogeochemistry Interactions in the Tropical Ocean" and through several research cruises with $\mathrm{R} / \mathrm{V}$ Meteor and $\mathrm{R} / \mathrm{V}$ Maria S. Merian as well as by the Bundesministerium für Bildung und Forschung as part of the Verbundvorhaben NORDATLANTIK (03F0443B) and RACE (03F0651B). The authors also acknowledge the PIRATA program for free data access.Open Access This article is distributed under the terms of the Creative Commons Attribution License which permits any use, distribution, and reproduction in any medium, provided the original author(s) and the source are credited.

\section{Appendix 1: Comparison of TropFlux and PIRATA derived surface heat fluxes}

To evaluate the TropFlux net surface heat fluxes, the seasonal cycles of the latent and sensible heat fluxes were estimated from the PIRATA observations using the COARE algorithm (Fairall et al. 2003). In addition, the contribution of the long-wave radiation as given by daSilva et al. (1994) was compared to TropFlux. In general, the different estimates for the individual terms agree rather well with maximum discrepancies of $20 \mathrm{~W} \mathrm{~m}^{-2}$ (Table 2; Fig. 7) for the combined net surface heat flux (shortwave

Table 2 Average differences between the monthly estimates of individual contributions to the surface heat flux from TropFlux and PIRATA

\begin{tabular}{|c|c|c|c|c|}
\hline & $0^{\circ} \mathrm{N}, 23^{\circ} \mathrm{W}$ & $0^{\circ} \mathrm{N}, 10^{\circ} \mathrm{W}$ & $0^{\circ} \mathrm{N}, 0^{\circ} \mathrm{E}$ & $10^{\circ} \mathrm{S}, 10^{\circ} \mathrm{W}$ \\
\hline \multicolumn{5}{|c|}{ Average difference in surface heat flux components between TropFlux and PIRATA/daSilva (for outgoing longwave radiation) } \\
\hline Incoming shortwave radiation $\left(\mathrm{W} \mathrm{m}^{-2}\right)$ & $5.8 \pm 4.5$ & $14.4 \pm 11$ & $9.4 \pm 9.1$ & $13.2 \pm 8.9$ \\
\hline Outgoing longwave radiation $\left(\mathrm{W} \mathrm{m}^{-2}\right)$ & $3.3 \pm 1.3$ & $4.6 \pm 2.7$ & $6.5 \pm 4.0$ & $7.2 \pm 3.1$ \\
\hline Latent heat flux $\left(\mathrm{W} \mathrm{m}^{-2}\right)$ & $15.0 \pm 7.1$ & $6.8 \pm 4.0$ & $9.3 \pm 4.5$ & $7.6 \pm 4.1$ \\
\hline Sensible heat flux $\left(\mathrm{W} \mathrm{m}^{-2}\right)$ & $1.1 \pm 1.2$ & $1.0 \pm 0.5$ & $1.7 \pm 1.1$ & $4.8 \pm 3.0$ \\
\hline Net heat flux $\left(\mathrm{W} \mathrm{m}^{-2}\right)$ & $10.7 \pm 9.8$ & $18.2 \pm 12.0$ & $20.0 \pm 7.6$ & $7.4 \pm 3.5$ \\
\hline \multicolumn{5}{|l|}{ Data coverage PIRATA compared to TropFlux } \\
\hline Incoming shortwave radiation $(\%)$ & 78 & 62 & 57 & 71 \\
\hline Latent/sensible heat flux $(\%)$ & 43 & 38 & 46 & 62 \\
\hline
\end{tabular}

As a measure of the spread of these average differences, the standard deviation of the difference is given. As additional information the amount of daily PIRATA observations is given as percentage of the gap-free daily TropFlux time-series between 1997 and 2012 (5844 days) 

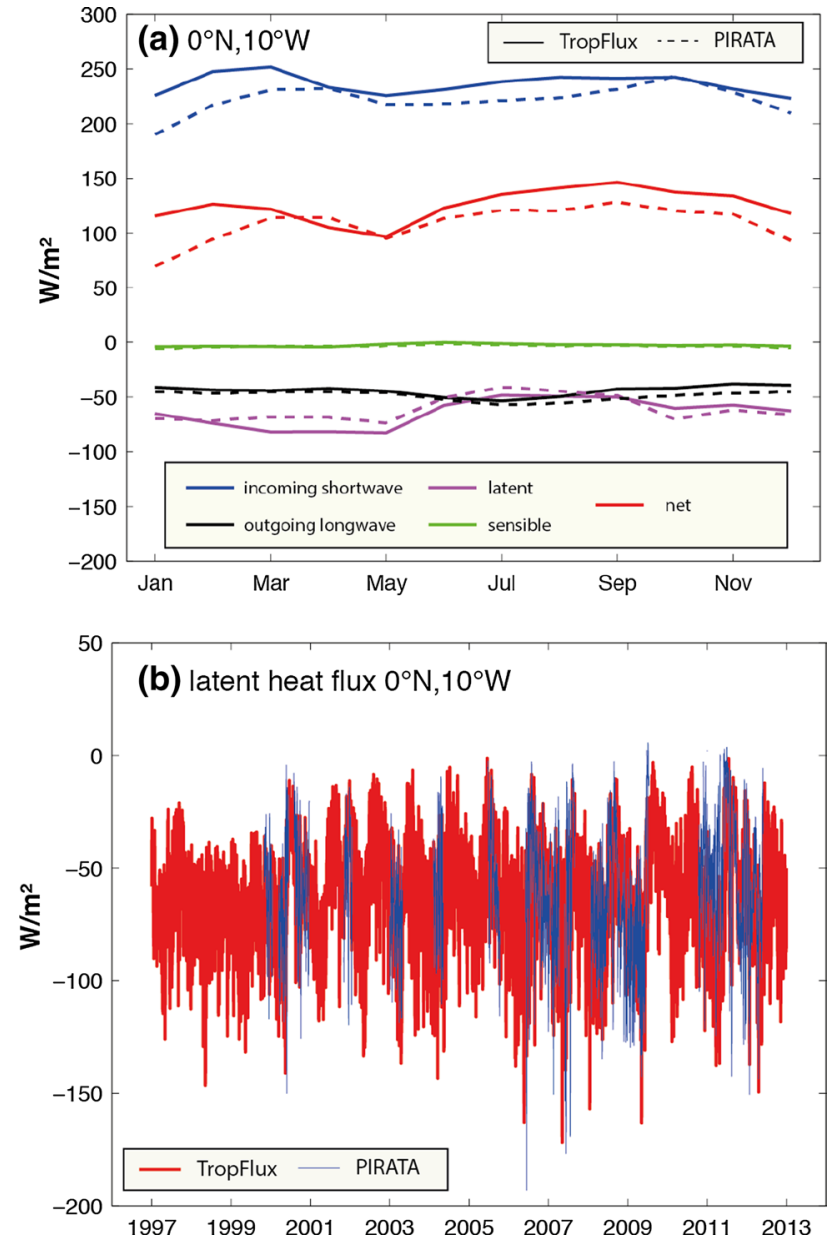

Fig. 7 a Comparison of the seasonal cycle at $0^{\circ} \mathrm{N}, 10^{\circ} \mathrm{W}$ of the different components of the net surface heat flux as obtained from TropFlux and PIRATA (incoming shortwave, latent and sensible heat flux)/daSilva (outgoing longwave), $\mathbf{b}$ daily estimates of the latent flux at $0^{\circ} \mathrm{N}, 10^{\circ} \mathrm{W}$ from TropFlux (red) and PIRATA (blue); the correlation coefficient for TropFlux and PIRATA is 0.57 (significant at the $95 \%$ confidence level) during the periods when they coexist

radiation + outgoing long-wave radiation + sensible heat flux + latent heat flux). This does not come as a surprise as the PIRATA data are included in the TropFlux product and latent and sensible heat fluxes are also evaluated with the COARE algorithm. However, some discrepancies exist, which can be probably explained by data gaps in the PIRATA records (Table 2) and by quality control procedures used to derive the TropFlux product. As some of the PIRATA estimates are based on a considerably smaller data base (e.g. only $38 \%$ of daily observations at $0^{\circ} \mathrm{N}, 10^{\circ} \mathrm{W}$ for latent and sensible heat flux compared to the gap-free TropFlux time series, Table 2) and TropFlux seems to provide reasonable estimates for all contributions to the net surface heat flux at these locations, TropFlux will be further used for the analysis of the ML heat budgets.

\section{Appendix 2: Uncertainties in heat advection terms due to choice of surface velocity product}

The variability of the estimates of the advection terms caused by the use of different surface velocity products is considered in the following. Two additional surface velocity products, namely the drifter climatology of Lumpkin and Garraffo (2005) and the OSCAR product (Bonjean and Lagerloef 2002) were used to calculate the advection terms. These two products are available on a $1^{\circ} \times 1^{\circ}$ grid in longitude and latitude and climatological monthly values are used. To illustrate the spread in the resulting advection terms an error bar is constructed as the standard deviation of the monthly advection term values, when the advection terms are estimated with the different surface velocity products (Fig. 8, top panels). In general, the uncertainty of the advection terms is larger in the second half of the year at all locations. Dependent on the surface velocity product, not only the magnitude, but also the sign of the resulting advection term can differ during different periods within the year. This is due to opposing velocities among the products, e.g. in spring and autumn at $23^{\circ} \mathrm{W}$ for the zonal as well as the meridional velocity (Fig. 8, lower panels). Particularly meridional velocities at $23^{\circ} \mathrm{W}$, which are negative (against the wind) in the drifter climatology of Lumpkin and Garraffo (2005) and hardly existent in the OSCAR product within the entire equatorial Atlantic, lead to the use of the combined (ARGO and drifter) surface velocity product for this study. In summary, it appears that additional work has to be done to improve surface velocities within the equatorial Atlantic as they alter the effect of the heat advection terms on the ML heat budget.

\section{Appendix 3: Error estimates}

Total errors of each monthly estimate of the individual terms contributing to the heat budget of the ML are com-

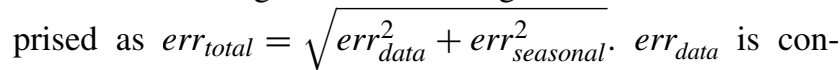
sidered as an error inherent to the instrumentation or the algorithms used to derive the estimate and is usually given by the data provider. For the TropFlux product Foltz et al. (2013) find the monthly err data for the different heat flux components to be $8 \mathrm{~W} \mathrm{~m}^{-2}$ for latent heat flux and shortwave radiation, $2 \mathrm{~W} \mathrm{~m}^{-2}$ for outgoing long-wave radiation and $1 \mathrm{~W} \mathrm{~m}^{-2}$ for sensible heat flux, accordingly for the wind stress $0.004 \mathrm{~N} \mathrm{~m}^{-2}$ is calculated. The accuracy of PIRATA temperatures is given as $0.03{ }^{\circ} \mathrm{C}$ (Freitag 1994). For TMI SST an error of $0.1{ }^{\circ} \mathrm{C}$ is considered (http://www.ssmi.com/tmi/tmi_validation.html).

$e r r_{\text {seasonal }}$ is the statistical uncertainty of each monthly estimate resulting from a finite length of the data record 

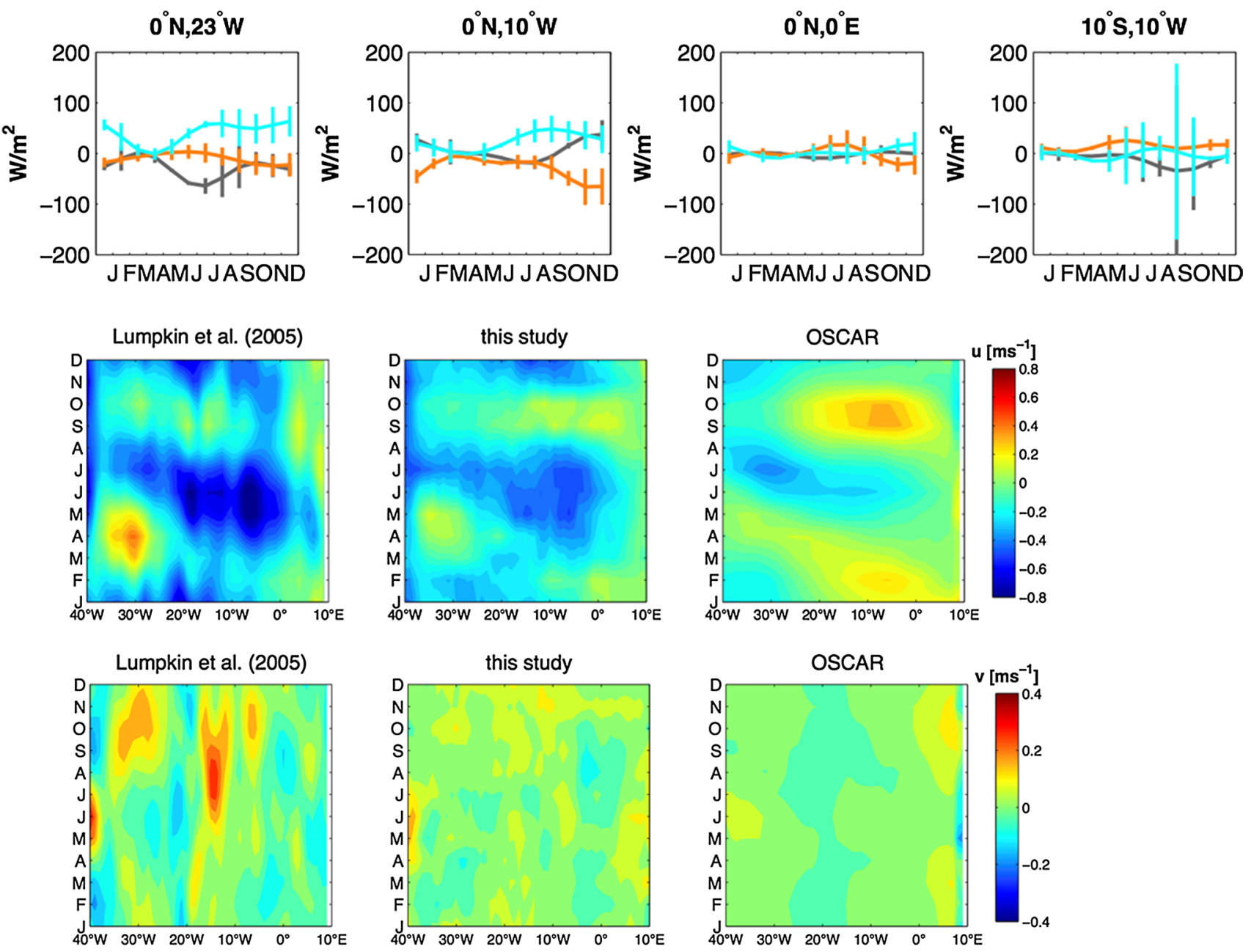

Fig. 8 Top The advection terms at the four locations within the ACT: zonal heat advection in grey, meridional heat advection in orange and eddy heat advection in cyan calculated for the surface velocities used in this study (combined ARGO and drifter velocities). The error bars are constructed as the standard deviation of monthly values derived by using the different surface climatology products (see text for details). Bottom Seasonal cycle of equatorial zonal (u) and meridional (v) surface velocities for the different velocity products and is estimated as the standard error (SE) of each calendar month.

Concerning the surface velocities, no statement about the individual data error of drifter velocities could be found on the website (www.aoml.noaa.gov/phod/dac/). However, the natural oceanic variability in monthly surface currents, which is dominated by averaging over TIWs, is much larger than the data error for these individual observations. Hence for the surface velocities $e r r_{\text {total }}=e r r_{\text {seas }}$ and is estimated as the SE for all independent velocity estimates (ARGO and drifter) falling in a grid box within each month of the year.

As the uncertainty for terms associated with turbulent mixing is described in terms of $95 \%$ confidence limits (Hummels et al. 2013), all uncertainties ( err $\left._{\text {total }}\right)$ within this study are converted to $95 \%$ confidence limits (CL95) for consistency. The conversion from SE to CL95 is via $C L 95=\bar{x} \pm 1.96 \cdot S E$, whereas $\bar{x}$ is the monthly average of term $\mathrm{x}$.
CL95 for turbulent dissipation rates are derived via bootstrapping (Hummels et al. 2013), as dissipation rates are not distributed log-normally and therefore the standard error should not be used.

To derive error estimates for terms comprised of different variables, which are attributed with their individual errors estimated as described above, standard error propagation is used.

\section{References}

Athie G, Marin F (2008) Cross-equatorial structure and temporal modulation of intraseasonal variability at the surface of the Tropical Atlantic Ocean. J Geophys Res Oceans 113. doi:10.1029/200 $7 \mathrm{jc} 004332$

Bonjean F, Lagerloef GSE (2002) Diagnostic model and analysis of the surface currents in the tropical Pacific Ocean. J Phys Oceanogr 
32:2938-2954. doi:10.1175/1520-0485(2002)032<2938:dmaaot> 2.0.co; 2

Bourlès B, Lumpkin R, McPhaden MJ, Hernandez F, Nobre P, Campos E, Yu LS, Planton S, Busalacchi A, Moura AD, Servain J, Trotte J (2008) The PIRATA program: History, accomplishments, and future directions. Bull Am Meteorol Soc 89:1111-+. doi: 10.1175/2008bams2462.1

Brandt P, Caniaux G, Bourlès B, Lazar A, Dengler M, Funk A, Hormann V, Giordani H, Marin F (2011a) Equatorial upper-ocean dynamics and their interaction with the West African monsoon. Atmos Sci Lett 12:24-30. doi:10.1002/asl.287

Brandt P, Funk A, Hormann V, Dengler M, Greatbatch RJ, Toole JM (2011b) Interannual atmospheric variability forced by the deep equatorial Atlantic Ocean. Nature 473:497-500. doi:10.1038/ nature 10013

Bunge L, Provost C, Kartavtseff A (2007) Variability in horizontal current velocities in the central and eastern equatorial Atlantic in 2002. J Geophys Res Oceans 112. doi:10.1029/200 6jc003704

Cane MA, Moore DW (1981) A note on low-frequency equatorial basin modes. J Phys Oceanogr 11:1578-1584. doi:10.1175/1520-0485(1981)011<1578:ANOLFE >2.0.CO;2

Caniaux G, Giordani H, Redelsperger J-L, Guichard F, Key E, Wade M (2011) Coupling between the Atlantic cold tongue and the West African monsoon in boreal spring and summer. J Geophys Res Oceans 116:C04003. doi:10.1029/2010JC006570

Chang P (1993) Seasonal cycle of sea surface temperature and mixed layer heat budget in the tropical Pacific Ocean. Geophys Res Lett 20:2079-2082. doi:10.1029/93GL02374

Chang P, Yamagata T, Schopf P, Behera SK, Carton J, Kessler WS, Meyers G, Qu T, Schott F, Shetye S, Xie SP (2006) Climate fluctuations of tropical coupled systems - The role of ocean dynamics. J Clim 19:5122-5174. doi:10.1175/jcli3903.1

da Silva A, Young AC, Levitus S (1994) Atlas of surface marine data 1994, volume 1.: Algorithms and procedures. Tech Rep 6, US Department of Commerce, NOAA, NESDIS

de Boyer Montégut C, Madec G, Fischer AS, Lazar A, Iudicone D (2004) Mixed layer depth over the global ocean: an examination of profile data and a profile-based climatology. J Geophys Res 109. doi: $10.1029 / 2004 \mathrm{JC} 002378$

Ding H, Keenlyside NS, Latif M (2009) Seasonal cycle in the upper equatorial Atlantic Ocean. J Geophys Res Oceans 114:C09016. doi:10.1029/2009JC005418

Fairall CW, Bradley EF, Hare JE, Grachev AA, Edson JB (2003) Bulk parameterization of air-sea fluxes: updates and verification for the COARE algorithm. J Clim 16:571-591. doi:10.1175/1520-0442(2003)016<0571:bpoasf $>2.0$. co;2

Foltz GR, Grodsky SA, Carton JA, McPhaden MJ (2003) Seasonal mixed layer heat budget of the tropical Atlantic Ocean. J Geophys Res Oceans 108. doi:10.1029/2002jc001584

Foltz GR, Schmid C, Lumpkin R (2013) Seasonal cycle of the mixed layer heat budget in the northeastern tropical Atlantic Ocean. J Clim. doi:10.1175/JCLI-D-13-00037.1

Freitag HP (1994) Calibration procedures and instrumental accuracy estimates of TAO temperature, relative humidity and radiation measurements. U.S. Department of Commerce, National Oceanic and Atmospheric Administration, Environmental Research Laboratories, Pacific Marine Environmental Laboratory

Gouriou Y, Reverdin G (1992) Isopycnal and diapycnal circulation of the upper equatorial Atlantic Ocean in 1983-1984. J Geophys Res Oceans 97:3543-3572. doi:10.1029/91JC02935

Gregg MC (1998) Estimation and geography of diapycnal mixing in the stratified ocean. In: Physical processes in lakes and oceans, vol 54. Coastal Estuarine Stud. AGU, Washington, DC, pp 305338. doi:10.1029/CE054p0305
Gregg MC, Peters H, Wesson JC, Oakey NS, Shay TJ (1985) Intensive measurements of turbulence and shear in the equatorial undercurrent. Nature 318:140-144. doi:10.1038/318140a0

Hinze JO (1975) Turbulence. McGraw-Hill, New York

Hummels R (2012) On the variability of turbulent mixing within the upper layers of the Atlantic Cold Tongue region. Universitätsbibliothek Kiel, $\mathrm{PhD}$

Hummels R, Dengler M, Bourlès B (2013) Seasonal and regional variability of upper ocean diapycnal heat flux in the Atlantic cold tongue Progress in Oceanography 111:52-74. doi:10.1016/j.pocean.2012.11.001

Inoue R, Lien RC, Moum JN (2012) Modulation of equatorial turbulence by tropical instability wave. J Geophys Res Oceans 117. doi:10.1029/2011JC007767

Jochum M, Murtugudde R (2006) Temperature advection by tropical instability waves. J Phys Oceanogr 36:592-605. doi:10.1175/jpo2870.1

Josey SA, Kent EC, Taylor PK (1999) New insights into the ocean heat budget closure problem from analysis of the SOC air-sea flux climatology. J Clim 12:2856-2880. doi:10.1175/1520-0442(1999)012<2856:niitoh>2.0.co;2

Jouanno J, Marin F, du Penhoat Y, Molines JM, Sheinbaum J (2011a) Seasonal modes of surface cooling in the Gulf of Guinea. J Phys Oceanogr 41:1408-1416. doi:10.1175/jpo-d-11-031.1

Jouanno J, Marin F, du Penhoat Y, Sheinbaum J, Molines JM (2011b) Seasonal heat balance in the upper $100 \mathrm{~m}$ of the equatorial Atlantic Ocean. J Geophys Res Oceans 116. doi:10.1029/2010jc006912

Jouanno J, Marin F, du Penhoat Y, Molines J-M (2013) Intraseasonal modulation of the surface cooling in the Gulf of Guinea. J Phys Oceanogr 43:382-401. doi:10.1175/jpo-d-12-053.1

Kushnir Y, Robinson WA, Chang P, Robertson AW (2006) The physical basis for predicting Atlantic sector seasonal-to-interannual climate variability. J Clim 19:5949-5970. doi:10.1175/jcli3943.1

Lebedev KV, Yoshinari H, Maximenko NA, Hacker PW (2007) YoMaHa'07: Velocity data assessed from trajectories of Argo floats at parking level and at the sea surface. IPRC Technical Note No. 4(2): $16 \mathrm{p}$

Lien RC, Caldwell DR, Gregg MC, Moum JN (1995) Turbulence variability at the equator in the central Pacific at the beginning of the 1991-1993 El Niño. J Geophys Res Oceans 100:6881-6898. doi:10.1029/94JC03312

Lien RC, D'Asaro EA, Menkes CE (2008) Modulation of equatorial turbulence by tropical instability waves. Geophys Res Lett 35 . doi:10.1029/2008gl035860

Lorbacher K, Dommenget D, Niiler PP, Köhl A (2006) Ocean mixed layer depth: a subsurface proxy of ocean-atmosphere variability. J Geophys Res Oceans 111:C07010. doi:10.1029/2003JC002157

Lumpkin R, Garraffo Z (2005) Evaluating the decomposition of tropical Atlantic drifter observations. J Atmos Ocean Technol 22:1403-1415. doi:10.1175/jtech1793.1

Lumpkin R, Grodsky SA, Centurioni L, Rio M-H, Carton JA, Lee D (2013) Removing spurious low-frequency variability in drifter velocities. J Atmos Ocean Technol 30:353-360. doi:10.1175/JTECH-D-12-00139.1

Marin F, Caniaux G, Bourles B, Giordani H, Gouriou Y, Key E (2009) Why were sea surface temperatures so different in the eastern equatorial Atlantic in June 2005 and 2006? J Phys Oceanogr 39:1416-1431. doi:10.1175/2008jpo4030.1

Moisan JR, Niiler PP (1998) The Seasonal Heat Budget of the North Pacific: net Heat Flux and Heat Storage Rates (1950-1990). J Phys Oceanogr 28:401-421. doi:10.1175/1520-0485(1998)028<0401:TSHBOT>2.0.CO;2

Moum JN, Caldwell DR (1985) Local Influences on Shear-Flow Turbulence in the Equatorial. Ocean Sci 230:315-316. doi:10.1126/ science. 230.4723 .315 
Moum JN, Caldwell DR, Paulson CA (1989) Mixing in the equatorial surface layer and thermocline. J Geophys Res Oceans 94:20052022. doi:10.1029/JC094iC02p02005

Moum JN, Gregg MC, Lien RC, Carr ME (1995) Comparison of turbulence kinetic energy dissipation rate estimates from two ocean microstructure profilers. J Atmos Ocean Technol 12:346-366. doi:10.1175/1520-0426(1995)012<0346:COTKED>2.0.CO;2

Moum JN, Lien RC, Perlin A, Nash JD, Gregg MC, Wiles PJ (2009) Sea surface cooling at the Equator by subsurface mixing in tropical instability waves. Nat Geosci 2:761-765. doi:10.1038/ngeo657

Moum JN, Perlin A, Nash JD, McPhaden MJ (2013) Seasonal sea surface cooling in the equatorial Pacific cold tongue controlled by ocean mixing. Nature 500:64-67. doi:10.1038/nature12363

Oakey NS (1982) Determination of the rate of dissipation of turbulent energy from simultaneous temperature and velocity shear microstructure measurements. J Phys Oceanogr 12:256-271. doi:10.1175/1520-0485(1982)012<0256:DOTR $\mathrm{OD}>2.0 . \mathrm{CO} ; 2$

Osborn TR (1980) Estimates of the local rate of vertical diffusion from dissipation measurements. J Phys Oceanogr 10:83-89. doi:10.1175/1520-0485(1980)010<0083:EOTLRO > 2.0.CO;2

Pazan SE, Niiler PP (2001) Recovery of near-surface velocity from undrogued drifters. J Atmos Ocean Technol 18:476-489. doi:10.1175/1520-0426(2001)018<0476:ronsvf >2.0.co;2

Perez RC, Hormann V, Lumpkin R, Brandt P, Johns WE, Hernandez F, Schmid C, Bourlès B (2013) Mean meridional currents in the central and eastern equatorial. Atlant Clim Dyn 1-20. doi:10.1007/s00382-013-1968-5

Peter AC, Le Henaff M, du Penhoat Y, Menkes CE, Marin F, Vialard J, Caniaux G, Lazar A (2006) A model study of the seasonal mixed layer heat budget in the equatorial. Atlant J Geophys Res Oceans 111. doi: $10.1029 / 2005 j \mathrm{j} 003157$

Peters H, Gregg MC, Toole JM (1988) On the parameterization of equatorial turbulence. J Geophys Res Oceans 93:1199-1218. doi: 10.1029/JC093iC02p01199

Pope SB (2000) Turbulent flows. Cambridge University Press, Cambridge
Prandke H, Stips A (1998) Test measurements with an operational microstructure-turbulence profiler: detection limit of dissipation rates. Aquat Sci 60:191-209. doi:10.1007/s000270050036

Praveen Kumar B, Vialard J, Lengaigne M, Murty VSN, McPhaden MJ (2012) TropFlux: air-sea fluxes for the global tropical oceans-description and evaluation. Clim Dyn 38:1521-1543. doi:10.1007/s00382-011-1115-0

Reynolds RW, Smith TM (1994) Improved global sea surface temperature analyses using optimum interpolation. J Clim 7:929-948. doi:10.1175/1520-0442(1994)007<0929:IGSSTA>2.0.CO;2

Rhein M, Dengler M, Sultenfuss J, Hummels R, Huttl-Kabus S, Bourles B (2010) Upwelling and associated heat flux in the equatorial Atlantic inferred from helium isotope disequilibrium. J Geophys Res Oceans 115. doi:10.1029/2009jc005772

Schafstall J, Dengler M, Brandt P, Bange H (2010) Tidal-induced mixing and diapycnal nutrient fluxes in the Mauritanian upwelling region. J Geophys Res Oceans 115. doi:10.1029/2009jc005940

Stevenson JW, Niiler PP (1983) Upper ocean heat budget during the Hawaii-to-Tahiti Shuttle Experiment. J Phys Oceanogr 13:1894 1907. doi:10.1175/1520-0485(1983)013<1894:UOHBDT>2.0.CO;2

Swenson MS, Hansen DV (1999) Tropical Pacific ocean mixed layer heat budget: the Pacific cold tongue. J Phys Oceanogr 29:69-81. doi:10.1175/1520-0485(1999)029<0069:tpomlh>2.0.co;2

Thierry V, Treguier A-M, Mercier H (2004) Numerical study of the annual and semi-annual fluctuations in the deep equatorial. Atlan Ocean Ocean Modell 6:1-30. doi:10.1016/ S1463-5003(02)00054-9

von Schuckmann K, Brandt P, Eden C (2008) Generation of tropical instability waves in the Atlantic Ocean. J Geophys Res Oceans 113. doi: $10.1029 / 2007 \mathrm{jc} 004712$

Wade M, Caniaux G, du Penhoat Y (2011) Variability of the mixed layer heat budget in the eastern equatorial Atlantic during 2005 2007 as inferred using Argo floats. J Geophys Res Oceans 116. doi:10.1029/2010jc006683

Wang WM, McPhaden MJ (1999) The surface-layer heat balance in the equatorial Pacific Ocean. Part I: Mean seasonal cycle. J Phys Oceanogr 29:1812-1831. doi:10.1175/1520-0485(1999)029<1812:tslhbi> 2.0.co;2 